\title{
1 The Capability of Sentinel-MSI (2A/2B) and Landsat-OLI (8/9) 2 for Seagrass and Algae Species Differentiation using Spectral 3 Reflectance
}

4 Abderrazak Bannari ${ }^{1}$, Thamer Salim Ali $^{2}$ and Asma Abahussain ${ }^{2}$

$5 \quad{ }^{1}$ Space Pix-Map International Inc., Gatineau (Québec) J8R 3R7, Canada. Email: abannari@bell.net

$6{ }^{2}$ Department of Natural Resources and Environment, College of Graduate Studies, Arabian Gulf University, Manama, Kingdom of Bahrain, P.O. Box: 26671, Tel: (973) 1723-9545; Fax: (973) 1723-9552.

Correspondence to: Abderrazak Bannari, Email: abannari@bell.net

Abstract. This paper assesses the reflectance difference values between the homologous visible and near-infrared (VNIR) spectral bands of Sentinel-MSI-2A/2B and Landsat-OLI-8/9 sensors for seagrass, algae, and mixed species discrimination and monitoring in a shallow marine environment southeastern of Bahrain in the Arabian Gulf. To achieve these, a field survey was conducted to collect samples of seawater, underwater sediments, seagrass (Halodule uninebell.netrvis and Halophila stipulacea) and algae (green and brown). As well, an experimental mode was established in a Goniometric-Laboratory to simulate the marine environment, and spectral measurements were performed using an ASD spectroradiometer over each separate and different case of seagrass and algae mixed species at different coverage rate $(0,10,30,75$, and $100 \%)$ considering the bottom sediments with clear and dark colors. All measured spectra were analyzed and transformed using continuum-removed reflectance spectral (CRRS) approach to assess spectral separability among separate or mixed species at varying coverage rates. Afterward, the spectra were resampled and convolved in the solar-reflective spectral bands of MSI and OLI sensors and converted into water vegetation indices (WVI) to investigate the potential of red, green, and blue bands for seagrass and algae species discrimination. For comparison and sensor differences quantification, statistical fits $(p<0.05)$ were conducted between reflectances in homologous bands and also between homologous WVI; as well as the coefficient of determination $\left(\mathrm{R}^{2}\right)$ and root mean square difference (RMSD) were calculated. The results of spectral and CRRS analyses highlighted the importance of the blue, green, and NIR wavelengths for seagrass and algae detection and probable discrimination based on hyperspectral measurements. However, when resampled and convolved in MSI and OLI bands, spectral information loses the specific and unique absorption features and becomes more generalized and less precise. Therefore, relying on the multispectral bandwidth of MSI and OLI sensors, it is difficult or even impossible to differentiate or to map seagrass and algae individually at the species level. Additionally, instead of the red band, the integration of the blue or the green bands in WVI increases their discriminating power of submerged aquatic vegetation (SAV), particularly Water Adjusted Vegetation Index (WAVI), Water Enhance Vegetation Index (WEVI), and Water Transformed Vegetation Index (WTDVI) indices. These results corroborate the spectral analysis and the CRRS transformations that the blue and green electromagnetic radiation allows better marine vegetation differentiation. However, despite the power of blue wavelength to penetrate deeper into the water, 
Furthermore, statistical fits between the reflectance in the VNIR homologous bands of SMI and OLI revealed excellent linear relationships $\left(\mathrm{R}^{2}\right.$ of 0.999$)$ with insignificant $\mathrm{RMSD}(\leq 0.0015)$. Important agreements $\left(0.63 \leq \mathrm{R}^{2} \leq 0.96\right)$ were also obtained between homologous WVI regardless of the integrated spectral bands (i.e., red, green, and blue), yielding insignificant RMSD $(\leq 0.01)$. Accordingly, these results pointed out that MSI and OLI sensors are spectrally similar, and their data can be used jointly to monitor accurately the spatial distribution of SAV and its dynamic in time and space in shallow marine environment, provided that rigorous data pre-processing issues are addressed.

\section{Introduction}

Seagrass meadows are identified as an important key for the characterization of environmental resources in estuarine and shallow coastal areas, and a fundamental health index allowing the assessment of coastal ecosystems. The composition and density of their species depend largely on water depth, temperature, salinity, coastal substrate material, and light penetration (Dierssen et al., 2015). Adapted to grow in shallow seawater down to a depth of $20 \mathrm{~m}$, where approximately only $11 \%$ of surface light reaches the bottom (Duarte and Gattuso, 2008), they play an essential role in the sustainability of global ecosystem biodiversity in most shallow near-shore areas around the world (DenHartog, 1970; Konstantinos et al., 2016). Moreover, the biodiversity of seagrass provides secure habitat and food for a wide variety of marine micro-organisms, improve the quality of water and protect shorelines against erosion in the middle and lower intertidal and sub-tidal zones (Roelfsema et al., 2009; Anders and Lina, 2011; Yang and Yang, 2012; Morrison et al., 2014). Like other vegetation cover, seagrass beds play an important role in carbon storage (Novak and Short, 2020), as well as effective removal of carbon dioxide from the "biosphere-atmosphere" system, which significantly mitigates the climate change impacts (Duarte et al., 2013; Lyimo, 2016). Although occupying only $0.2 \%$ of the world's oceans (Traganos, 2020), seagrass beds can store twice as much as forests, and sequester around 10\% of the total carbon received by the oceans (Fourqurean et al., 2012).

Unfortunately, natural and anthropogenic disturbances and disasters have led to the decline of seagrass around the world (Green and Short, 2003; Orth et al., 2006; Grech et al., 2012; Wood, 2012) at local and regional scales. Undoubtedly, these causes substantially destroy the seagrass beds and biota associated in such habitat and unbalance the ecological functions of coastal zones. Short et al. (2011) showed that seagrass habitat disappeared worldwide at a rate of $110 \mathrm{~km}^{2}$ per year between 1980 and 2006. Hence, understanding the spatial distribution of seagrass biomass, its extent, condition, and change over time is essential for their monitoring, management, and protection (Short and Coles, 2001; Waycott et al., 2009). Such monitoring provides updated and accurate information useful for the protection of several ecosystems (Leleu et al., 2012), conservation (Hamel and Andréfouët, 2010), coastal risk assessment (Warren et al., 2016), ecological resources development (Boström et al., 2011), and marine spatial planning (Saarman et al., 2012; Kibele, 2017). In addition, mapping and inventorying the total aboveground biomass of seagrass and algae are important for ecosystem health assessment (Short and Wyllie-Echeverria, 1996), alteration and dynamics in space-time (Neckles et al., 2012), biomass productivity and its contribution to the global biosphere carbon sink capacity (Waycott et al., 2009), and understanding the impacts of climate change (Hashim et al., 2014). 
In the Arabian Gulf, the extreme environmental conditions combined with major seasonal variations in the marine environment promote the development of three seagrass species including Halodule uninervis which is the most dominant species, Halophila stipulacea that is less common, and Halophila ovalis, which is widely scattered and rarely forms relatively dense meadows. Along the western coast of the Arabian Gulf, these three species are reported and several species of marine algae are described, especially green and brown algae (Erftemeijer and Shuail, 2012). This natural resource is located in shallow waters with depths ranging from the intertidal zone to $20 \mathrm{~m}$, supporting the second largest population of dugongs (Dugong dugon) in the world (Preen, 2004); as well as a large population of Green Turtles (Chelonia mydas) and Hawksbill Turtles (Eretmochelys imbricata) (Thakur et al., 2007). Unfortunately, these coastal ecosystems are under continuous threats from anthropogenic activities (Waycott et al., 2009), such as reclamation and dredging where several coastal developmental projects are constructed and others under construction (small islands projects development), industrial effluents, oil exploration, pipeline laying, maritime transportation, intensive circulation of commercial fishing boats, pollution and discharges of seawater desalinization and wastewater into the sea (Onuf, 1994; Dunton and Schonberg, 2002; Burfeind and Stunz, 2006; Humood, 2011; Erftemeijer and Shuail, 2012). Eventually, these activities catalyze the degradation and destruction of seagrass species and related ecosystems. Therefore, the assessment of seagrass conditions associated with broad scale of benthic species should be based on relevant and accurate information to measure several health indicators of coastal areas to ensure the sustainable development of these natural resources.

Previously, photo-interpretation approaches based on aerial photography have been adopted to follow seagrass and algae species development and assessment in space and time (Ferguson and Wood, 1990; Meehan et al., 2005; Mount, 2007). Afterward, the first generation of satellite remote sensing was used to investigate the seagrass classes' composition, differentiation, classification, etc. (Ackleson and Klemas, 1987; Hossain et al., 2014; Komatsu et al., 2020). Unfortunately, these goals were difficult to achieve accurately because the radiometric and spectral resolutions of sensors lacked the sensitivity to discriminate among different marine vegetation species and fragmented classes (Mumby et al., 1997; Wicaksono and Hafizt, 2013). To improve land-water surfaces reflectivity and information extraction, recent developments in remote sensing science and technology have led to an improvement of sensors performance in spatial and spectral resolutions, assuming a potential mapping of the marine environment and aquatic vegetation at the species level; obviously, if species under investigation have distinct spectral signatures. For instance, the Multi-Spectral Instruments (MSI) onboard Sentinel 2A and 2B, as well as the Operational Land Imager (OLI) sensors onboard Landsat 8 and 9 platforms were designed with a significant improvement of the signal-to-noise ratio (SNR) and radiometric performances (Knight and Kvaran, 2014). The availability of this new generation of sensors offers innovative opportunities for long-term high-temporal frequency for Earth surfaces' observation and monitoring (Mandanici and Bitelli, 2016). The free availability of their data significantly advances the applications of remote sensing with medium spatial resolutions (Roy et al., 2014; Wulder et al., 2015; Zhang et al., 2018). Thanks to the improvement of their spectral, radiometric, and temporal resolutions, they can expand the range of their applications to several natural resources and environmental domains for monitoring, assessing, and investigating (Hedley et al., 2012a and 2012b). Moreover, the orbits of these four satellites constellation are designed to ensure a revisiting interval time of less than 2 days ( $\mathrm{Li}$ and Roy, 2017; Li and Chen, 2020), thereby substantially increasing the monitoring 
capabilities of the Earth's surface and ecosystems (Drusch et al., 2012). Their spectral resolutions and configurations are designed in such a way that there is a significant match between the homologous spectral bands (Drusch et al., 2012; Irons et al., 2012). However, depending on the sensitivity of the intended application (Flood, 2017), the sensor radiometric drift calibration (Markham et al., 2016), the atmospheric corrections (Vermote et al., 2016), the surface reflectance anisotropy (Roy et al., 2017), and the sensors co-registration (Skakun et al., 2017; Yan et al., 2018), it is plausible that the natural surface-reflectances recorded by MSI and OLI sensors over the same target in the marine environment may be different. In addition, the relative spectral response profiles characterizing the filters (spectral responsivities) of these instruments are not perfectly identical between the homologous bands, so some differences are probably expected over the recorded land or water surfaces reflectance values and, therefore, their data cannot be reliably used together (Bannari et al., 2004; Van-derWerff and Van-der-Meer, 2016; Bannari, 2019). The importance of these differences depends on the application (spectral characteristics of the observed target) and on the approach adopted to perform time-series analyses, mapping, or change detection exploiting these instruments (Flood, 2017). For instance, it is plausible that the extraction of seagrass and/or algae information in time over shallow water areas using surface reflectances, empirical, semi-empirical, and/or physical approaches, may affect the comparison of the results.

The main objectives of this research focus on the analysis of Sentinel-MSI and Landsat-OLI homologous visible and near-infrared (VNIR) bands capability to distinguish and discriminate among seagrass (Halodule uninervis and Halophila stipulacea), algae (green and brown), and any probable case of mixed species of seagrass and algae sampled from the southeast area of Bahrain national water. To achieve these, the specific following steps are considered. 1) Examination of spectral signatures in VNIR wavelengths and their continuum-removal transformations for potential differentiation among the considered seagrass and algae species and their mixture submerged in seawater at different coverage rates, as well as considering the sediment-substrate with clear and dark colors. 2) Comparison and analysis of the difference between the resampled and convolved reflectances in the VNIR homologous bands of MSI and OLI sensors considering all examined samples. 3) Comparison between MSI and OLI sensors in terms of converting the reflectances over the considered samples at different coverage rates into several water vegetation indices (WVI). Finally, 4) efficiency and accuracy analysis of the examined WVI to discriminate between species (seagrass, algae and mixed) by integrating the green and blue bands instead of the red band. Further, according to these analyses results, it will be clear whether it possible for these sensors to differentiate between seagrass and algae effectively and precisely at the species level, or simply and generally to discriminate among submerged aquatic vegetation (SAV) cover at different density classes.

\section{Remote sensing of seagrass and algae detection and mapping: A review}

Traditional seagrass in-situ surveys require time and intensive field sampling, which is generally lack the spatial coverage and precision that are required to detect changes before they become irreversible or very difficult to maintain year after year (Peterson and Fourqurean, 2001, Yang and Yang, 2012). Over the recent decades, remote sensing science and sensors technology has played an essential role in seagrass mapping and monitoring (Dean and Salim, 2013; Dierssen et al., 2015). According to literature, the mapping of the characteristics and properties of seagrass and 
algae in the marine environment occurs over relatively small areas with limited variations in water depth and clarity using satellite, airborne, and drone remote sensing sensors (multispectral and hyperspectral). Moreover, field and laboratory in-situ measurements have been conducted for calibration and validation in several environments around the world (Larkum et al., 2006; Roelfsema et al., 2009; Hossain et al., 2014; Komatsu et al., 2020; Duffy et al. 2018).

Under laboratory conditions using spectral measurements, Thorhaug et al. (2007) demonstrated the near similarity in the shape and form of the spectral signatures of three different seagrass species with a very slight difference and pointed out subtle differences between marine algae (green and brown) and seagrass. In the central west coast of Florida in the USA, Pu et al. (2012) used in-situ Hyperspectral measurements in the field and laboratory to analyse the spectral behaviour and the potential discrimination among several seagrass species according to their spatial extent and abundance, water depths, and substrate types. They highlighted that the discrimination of seagrass species and the percentage of SAV coverage are affected by water depth and substrate on the measured spectra. Moreover, Wood (2012) demonstrated the potential of the synergy between the field spectra and hyperspectral data for seagrass sensing and mapping in Redfish Bay, Texas in the USA. Exploiting modeled and simulated data, Hedley et al. (2012a) demonstrated that Sentinel-MSI has an improved capability for detection and discrimination of the marine environment compared to SPOT-4 and Landsat-ETM+. Furthermore, Fyfe (2003) reported that the spectral signatures measured on harvested wet leaves (out of water) of different seagrass species were spectrally distinct. However, the real marine environment conditions are different from wet leaves due to water-column constituents including phytoplankton, suspended organic and inorganic matter, water depth variability, and optical properties of the underlying sediments (Pu et al., 2012).

Otherwise, NASA's Landsat program is the earliest and most commonly used over the past five decades, it consists of a series of nine satellite missions (1 to 9) using four types of multispectral sensors including MSS, TM, ETM +, and OLI (Bannari and Al-Ali, 2020) which have been used by many scientists to detect and map seagrass beds at local and regional scales (Ackleson and Klemas 1987; Luczkovich et al. 1993; Shapiro and Rohmann 2006; Phinn et al. 2008; Knudby and Nordlund, 2011; Lyons et al. 2012 and 2013; Kovacs et al. 2018). Exploring a time-series of 23 annual images acquired over the Eastern Banks of Moreton Bay in Australia, Lyons et al. (2013) demonstrated how Landsat TM and ETM+ data time-series analysis enabled seagrass distribution to be appropriately assessed in the context of its spatial and temporal history and provide the ability to not only quantify change but also describe the type of change. Moreover, a regional-scale mapping of seagrass habitat in the Wider-Caribbean region was achieved with acceptable accuracies using a total of 40 Landsat scenes acquired with TM and ETM+ sensors, and applying different images processing methods, i.e., segmentation, contextual editing, supervised classifications, etc. (Wabnitz et al., 2008). In Cam-Ranh Bay in Vietnam, Chen et al. (2016) investigated the temporal changes of seagrass beds over 20 years (1996 to 2015) by exploiting multi-temporal Landsat data acquired with TM, ETM+ and OLI sensors. Dekker et al. (2005) demonstrated that Landsat TM and ETM+ instruments did not have sufficient spectral and radiometric resolutions to discriminate among three seagrass species in a shallow coastal Australian lake. Contrariwise, Dahdouh-Guebas et al. (1999) reported the utility of Landsat-TM data associated with ground truth measurements to map accurately the distribution of seagrass and algae on the Kenyan coast. In addition to the Landsat sensor series, the European satellites such as SPOT-HRV were also used in combination with in-situ 
spectroradiometric measurements and quantitative semi-empirical models to assess the changes in the spatial distribution of seagrass biomass in Bourgneuf-Bay in France over 14 years (Barillé et al. 2010). Likewise, the potential of the Indian satellite (IRS-ID LISS-III) has been demonstrated for mapping the seagrass meadows extent in the Gulf of Mannar Biosphere Reserve in India (Umamaheswari et al., 2009).

Furthermore, the first generation of commercial satellites operated by the private remote sensing industry with very high pixel size and narrow spectral resolutions, such as IKONOS, Quickbird, WorldView, etc., offers complementary technology for seagrass sensing and mapping. This new technology provides an excellent compromise between spatial and spectral resolutions for information extraction. In clear water seagrass habitat in the Moreton-Bay (Australia), the spatial and temporal dynamics of seagrasses (cover, species, and biomass) have been studied from the leaf to patch scales between 2004 and 2013 integrating nine high spatial resolutions images acquired with WorldView2, IKONOS, and Quickbird-2 and applying object-image processing approach (Roelfsema et al., 2014). The results showed the utility of this new high spatial technology for time-series analysis and the derivation of seagrass products that are very useful in marine ecology management. Moreover, Knudby and Nordlund (2011) highlighted the utility of IKONOS data for seagrass detection in a patchy multi-species environment around Chumbe Island in Zanzibar (Tanzania). Along Zakinthos Island in Greece, Pasqualini et al. (2005) demonstrated that the SPOT-5 data with 2.5 and $10 \mathrm{~m}$ spatial resolutions are suitable for seagrass classes' classification according to the overall accuracies, but the pixel size of $2.5 \mathrm{~m}$ provided lower accuracy than $10 \mathrm{~m}$. In shallow waters of Moreton Bay in Australia, Phinn et al. (2008) have shown that the spatial and spectral resolutions of multispectral (Quickbird and Landsat-TM) and hyperspectral (airborne CASI) data affects the precision of seagrass biomass differentiation at the species level, i.e., when the pixel size increases the error is getting higher. Contrary to these findings, Dattola et al. (2018) reported the potential of the high spatial resolution of WorldView-2 compared to the medium resolution of Sentinel-MSI and Landsat-OLI for different seagrass species characterization in the Capo Rizzuto area in Italy. In addition, using QuickBird, CBERS (China-Brazil Earth Resources Satellite data), and Landsat-TM data to identify the spatial distribution of seagrass beds in Xincun Bay (Hainan province in China), Yang and Yang (2009) demonstrated that Quickbird data are more accurate than those of TM and CBERS sensors.

In addition to remote sensing sensor technologies, a variety of image processing methods have been employed in mapping seagrass spatial distribution and coverage. For instance, Marcello et al. (2018) demonstrated the good performance of support vector machines (SVM) approach compared to spectral angle mapper (SAM) and maximum likelihood for seagrass classification; moreover, they pointed out the greater aptitude of hyperspectral compared to multispectral data. Likewise, Peneva et al. (2008) reported that the maximum likelihood classification produced the highest overall accuracy while SAM yielded the lowest accuracy due to the predominant influence of water-column optical properties on the apparent spectral characteristics of seagrass and sand bottom in the northern Gulf of Mexico. For Posidonia oceanica mapping in the Mediterranean region, the random forests method gives more accurate results than SVM approaches when compared with in-situ observations (Bakirman and Gumusay, 2020). Whereas, using a high spatial resolution of WorldView-2 imagery acquired over a coastal area in Florida, the neural network classifier performed better than SVM for seagrass mapping (Perez et al., 2020). According to Uhrin and Townsend (2016), linear spectral mixture analysis (LSMA) can be used with photo interpretation to generate spatially resolved maps 
suitable for seagrass spatial distribution and provide improved estimates of seagrass classes. Nevertheless, Chen et al. (2016) revealed the difficulty and limitation of LSMA for mapping the fraction of scattered and heterogeneous seagrass patches that are smaller than the pixel size. At Ritchie's archipelago within the Andaman and Nicobar group of Islands, Bayyana et al. (2020) showed that Sentinel-MSI data can detect, and map submerged benthic habitat and seagrass beds present at a depth of $21 \mathrm{~m}$ using random forest, SVM, and K-nearest-neighbour classification algorithms. Besides, linear regressions were established between the field truth measurements and several vegetation indices derived from SPOT-XS, Landsat-TM, and CASI Hyperspectral airborne, to measure the density of seagrass in the tropical Western Atlantic (Mumby et al., 1997).

Since the emergence of remote sensing as a new scientific discipline in the early 1970s, vegetation indices (VI's) were involved as radiometric measurements of the spatial and temporal distribution of land vegetation photosynthetically active. They use the red and near-infrared (NIR) bands, the normalized difference vegetation index (NDVI) was proposed by Rouse et al. (1974) at the dawn of remote sensing. Since these two spectral bands are generally present on Earth observation and meteorological satellites, and often containing more than $90 \%$ of the information relating to vegetation canopy (Bannari et al., 1995), the NDVI had taken a privileged place in the NASA/NOAA Pathfinder project (James and Kalluri, 1994). Thus, it was daily derived from NOAA-AVHRR data at the Earth scale. Subsequently, it was also derived every day from MODIS and SPOT-Vegetation data to produce timeseries products for global vegetation assessment and monitoring at the regional and global scales. Due to this glorious history and its simplicity, the NDVI has become the most widely used to assess vegetation canopy. Then, this index was improved in a new version named soil adjusted vegetation index (SAVI) by Huete (1988) to minimize the artefacts caused by soil background on the estimation of vegetation cover fraction by incorporating a correction factor " $\mathrm{L}$ ". To overcome the limitations of linearity and saturation, to reduce the noise of atmospheric effects, and to remove the artefacts of soil optical properties, the enhanced vegetation index (EVI) was proposed also by Huete et al. (2002). Likewise, the transformed difference vegetation index (TDVI) was developed by Bannari et al. (2002) to describe the vegetation cover fraction independently to the background artefacts, to reduce the saturation problem, and to enhance the vegetation dynamic range linearly. These indices (NDVI, SAVI, EVI, and TDVI) were used to establish a close relationship between radiometric responses and land vegetative cover densities, and they were implemented in the ENVI image processing system.

In marine applications, these indices were tested by several scientists for seagrass and algae discrimination and mapping. For a spatiotemporal change in seagrass beds in Bourgneuf-Bay in France, the NDVI extracted from SPOTHRV images coupled with in-situ spectroradiometric data provided satisfactory results (Barillé et al., 2009). Using hyperspectral data, Dierssen et al. (2015) reported the potential of NDVI for SAV classes' discrimination. Similarly, Zoffoli et al. (2020) demonstrated the capability of NDVI derived from Sentinel-MSI data for seagrass percent cover estimation and leaf biomass mapping to characterize its seasonal dynamics along the European Atlantic coast. However, although VNIR bands are generally available in optical remote sensing satellites, it is well known that only the visible bands can penetrate ocean water deeper than NIR which is largely absorbed by the water surface (Kirk, 1994). Thus, regardless of the concentrations of suspended sediments and/or organic matter, the visible wavelengths are used to map the marine environment as the blue penetrates deeper $(\sim 37 \mathrm{~m})$ than any other wavelengths, followed 

by green $(\sim 30 \mathrm{~m})$, then red $(\sim 7 \mathrm{~m})$, and NIR (Fig. 1) penetrates the least, being attenuated in the shallowest depths around $2.5 \mathrm{~m}$ (Komatsu et al., 2020). Accordingly, blue, green, and red are the most suitable for sensing seagrass and SAV (Silva et al., 2008). Thereby, when vegetation indices are applied in the marine environment (Davranche et al., 2010; Zhao et al., 2013), always the red band is substituted by that of blue or green. Then, discussion was initiated on WVI or aquatic vegetation indices (AVI). For instance, when the red was replaced by the green in NDVI (Yang and Yang, 2009) and by the blue in SAVI (Villa et al., 2013) these versions were named, respectively, the Normalized Difference Aquatic Vegetation Index (NDAVI or WNDVI) and Water Adjusted Vegetation Index (WAVI). These two new versions were found more sensitive to seagrass LAI and percentage cover density, and discriminated better among species of seagrass (Yang and Yang, 2009; Villa et al., 2013). To separate and map vegetation features over some lake ecosystems in Italy, the NDAVI and the WAVI performed suitably (Villa et al., 2014). As well, for open water features delineation, Mcfeeters (1996) replaced the difference between "NIR and red" in the NDVI with that between "green and NIR", and he baptised this new combination the Normalized Difference Water Index (NDWI). In Taihu and Duck Lakes in China, NDVI and NDWI were used for wetland and SAV pattern delineation and classification (Lin et al., 2010; Zhao et al., 2013). Likewise, the visible atmospherically resistant index (VARI) was proposed by Gitelson et al. (2002a) to estimate the green vegetation fraction. While the triangular greenness index (TGI) was developed by Hunt et al. (2013) based on the chlorophyll absorption features. The capability of VARI and TGI was examined by Li (2018) who highlighted the advantage of VARI compared to TGI for seagrass biomass mapping in Core Banks in North Carolina in the USA. Proposed by Richardson and Wiegand (1977), the difference vegetation index (DVI) provided satisfactory results for mangrove cover and carbon stock estimation in the estuary and marine environment (Candra et al., 2016). Moreover, the difference-index between the blue and the green bands (DIF-BG) showed the best fits between observed and predicted SAV as reported by Mumby et al. (1997).

[ Figure 1 ]

\section{Materials and Methods}

Fig. 2 illustrates the followed methodology, which is based on a field survey to collect samples including seawater, sediments, seagrass (Halodule uninervis and Halophila stipulacea) and algae (green and brown) from shallow marine environment at different depths $(0.50$ to $7 \mathrm{~m})$ of southeast Bahrain. To simulate the marine environment, an experimental mode was established in a Goniometric-Laboratory and spectral measurements were performed using an Analytical Spectral Devices (ASD) spectroradiometer over each separate and mixed species at different coverage rate $(0,10,30,75$, and $100 \%)$, as well as simulating the seabed with dark and clear colors. To assess the spectral signatures variability that can be found among each separate or mixed species at varying coverage rates, all measured spectra were analyzed and transformed using continuum-removed reflectance spectral (CRRS) approach (see section 3.4). Then, the spectra were resampled and convolved in the solar-reflective spectral bands of MSI and OLI sensors using the Canadian Modified Simulation of a Satellite Signal in the Solar Spectrum (CAM5S) (Teillet and Santer, 1991) based on Herman radiative transfer code (RTC), and the relative spectral response profiles characterizing the filters of each instrument in the VNIR bands. Afterward, convolved spectra were converted into several WVI 
integrating the red, green, and blue bands. For comparison and sensor differences quantification, statistical fits were conducted using linear regression analysis $(p<0.05)$ between reflectances in homologous bands and between the examined homologous WVI derived from the two sensors data considering all samples, i.e., seawater, sediments, seagrass, and algae species (individually and mixed at the considered coverage rates). The coefficient of determination $\left(\mathrm{R}^{2}\right)$, difference values, and root mean square difference (RMSD) were calculated for reflectances and all versions of investigated WVI's.

[ Figure 2 ]

\subsection{Study Site}

The area under investigation in this research is the water boundary of the Kingdom of Bahrain $\left(25^{\circ} 32^{\prime}\right.$ and $26^{\circ} 00^{\prime} \mathrm{N}$, $50^{\circ} 20^{\prime}$ and 50 50'E) which is a group of islands located in the Arabian Gulf, east of Saudi Arabia and west of Qatar (Fig. 3). The archipelago comprises 33 islands, with a total area of $8269 \mathrm{~km}^{2}, 9 \%$ of it is a land area $\left(778.4 \mathrm{~km}^{2}\right)$. Along the southeast coast of Bahrain, the continental plateau extends for kilometers with a depth of less than one or two meters. The main island of Bahrain is surrounded by shoal areas named "Fashts" where depths do not exceed 10 $\mathrm{m}$ (Bannar $\mathrm{i}$ and Kadhem, 2018). These areas generally support a variety of species of seagrass, algae, coral, and fishes. Moreover, they play an important role in the hydrodynamic regime, which supports diverse biological ecosystems. Fig. 3 also illustrates the reclamation and dredging operations that have occurred in the study area over the past three decades where several coastal developmental projects are constructed, and others are in progress. These anthropogenic activities strongly contribute to the degradation and even to the destruction of seagrass species and associated coastal ecosystems.

[ Figure 3 ]

\subsection{Field sampling}

Seagrass and algae samples were collected on $4^{\text {th }}$ May 2017 from different meadows locations, which are characterized by a depth range from 0.5 to $7 \mathrm{~m}$ in the south and southeast waters of Bahrain (Fig. 4a). Some locations were dominated with Halodule uninervis (HU), others scattered, or dense patches were a mixture between $\mathrm{HU}$ and Halophila stipulacea (HS). HU is the most dominant species (Fig. 4b), it occurs as dense or scattered meadows patches along shoreline (Erftemeijer and Shail, 2012). This species is like grass with narrow leaves (around $3 \mathrm{~mm}$ in width and 25 $\mathrm{cm}$ in length). Whereas, HS (Fig. 4c) has darker green leaves reaching $10 \mathrm{~cm}$ in length and it is widely present in the Arabian Gulf. The brown (BA, Fig. 4d) and green (GA, Fig. 4e) algae were accessible near to shores and shallow water in general. In addition to the sediments (Fig. 4f) and pure seawater samples which were collected separately, samples of each seagrass and algae species were selected and harvested in healthy and fresh conditions from several stations within the study area, and then stored separately in non-translucent plastic bags with seawater and immediately placed in a cooler for transportation from the field to the laboratory. This was done to prevent structural and leaf 
pigment damages due to the delay between sampling time and spectroradiometric measurements in the GoniometricLaboratory.

[ Figure 4]

\subsection{Spectroradiometric measurements}

Spectroradiometric measurements were acquired in a dark BRDF Goniometric-Laboratory above each separated and mixed samples (Fig. 5) using an ASD spectroradiometer (ASD Inc., 2015). This instrument is equipped with two detectors operating in the VNIR and shortwave-infrared (SWIR), between 350 and $2500 \mathrm{~nm}$. It acquires a continuous spectrum with a $1.4 \mathrm{~nm}$ sampling interval from 350 to $1000 \mathrm{~nm}$ and $2 \mathrm{~nm}$ from 1000 to $2500 \mathrm{~nm}$. The ASD resamples the measurements in 1-nm intervals, which allows the acquisition of 2151 contiguous hyperspectral bands per spectrum. The sensor is characterized by the programming capacity of the integration time, which allows an increase of the SNR and stability. The data were acquired at nadir with a field of view (FOV) of $25^{\circ}$ and a solar zenith angle of approximately $5^{\circ}$ by averaging 40 measurements. The ASD was installed on a BRDF Goniometric-System with a height of approximately $65 \mathrm{~cm}$ over the target, which makes it possible to observe a surface of $\sim 830 \mathrm{~cm}^{2}$. A laser beam was used to locate the center of the ASD-FOV. The reflectance factor of each sample was calculated by rationing target radiance to the radiance obtained from a calibrated "Spectralon panel" according to the method described by Jackson et al. (1980). Moreover, the corrections were applied for the wavelength dependence and non-lambertien behavior of the panel (Sandmeier et al., 1998; ASD, 2015; Ben-Dor et al., 2015). The measurements were carried out above each collected sample including seawater, sediments, seagrass, and algae species as well as mixed species (seagrass and algae) considering different coverage rates $(0,10,30,75$, and 100\%). Each sample was placed and measured twice in black and clear-bright (yellow) large bowls, considering two sedimentary substrates (dark and clearbright) underlying the seagrass and algae samples that were submerged by seawater, i.e., simulating the aquatic environment. Since the remote sensing of benthic aquatic vegetation is mostly limited to the VNIR ranges (Fig. 1) only the wavelengths interval between 400 and $1000 \mathrm{~nm}$ are considered in our analyses.

[ Figure 5 ]

\subsection{Continuum-removed reflectance spectral (CRRS) transformation}

Spectral signatures are processed and transformed using numerous approaches to retrieve information regarding the change in reflectance of a particular target over a specific bandwidth between 350 and $2500 \mathrm{~nm}$ (Van-Der-Meera, 2004). For instance, absorption features (position, depth, width, and asymmetry) are used to quantitatively estimate the mineral, chemical, or physiological composition of samples from the measured spectra in the field, laboratory, and/or from hyperspectral images. To emphasize these absorption features, many approaches were proposed including relative absorption-band-depth (Crowley et al., 1989), spectral feature fitting technique, and Tricorder and Tetracorder algorithms (Clark et al., 2003). These approaches work on the so-called CRRS approach, thus recognizing that the absorption in a spectrum has a continuum and individual absorption features (Clark et al., 1987; Van-Der-Meera, 
2004; Clark et al., 2014). Proposed by Clark and Roush (1984), CRRS transformation and analysis allows the isolation of individual absorption features in the hyperspectral signature of a specific target under investigation, analysis, and comparison. It normalizes the original spectra and helps to compare individual absorption features from a common baseline (Clark et al., 1987). The continuum is a convex hull fit over the top of a spectrum under study using straightline segments that connect local spectra maxima. The first and last spectral data values are on the hull; therefore, the first and last bands in the output continuum-removed data file are equal to 1.0. In other words, after the continuum is removed, a part of the spectrum without absorption features will have a value of 1 , whereas complete absorption would be near to 0, and with most absorptions falling somewhere in between. The CRRS approach was used for discriminating and mapping rocks mineralogy (Clark et al., 1990; Clark and Swayze, 1995), land vegetation cover (Kokaly et al., 2003; Huang et al., 2004; Manevski et al., 2011), and seagrass and SAV (Barillé et al., 2011; Bargain et al., 2012; Wicaksono et al., 2019; Indayani et al., 2020). In this study, the continuum algorithm implemented in the ENVI image processing system was used (ENVI, 2012).

\subsection{Spectral sampling and convolving in MSI and OLI spectral bands}

Since 1972, the Landsat scientific collaboration program between NASA and USGS constitutes the continuous record of the Earth's surface reflectivity from space. Indeed, the Landsat satellites series support five decades of a global medium spatial resolution data collection, distribution, and archive of the Earth's surfaces (Bannari et al., 2004; Loveland and Dwyer, 2012) to support research, applications, and climate change impacts analysis at the global, the regional and the local scales (Roy et al., 2014 and 2016; Wulder et al., 2015). Benefiting from the acquired spaceengineering experience, from the heritage of Landsat instruments, and the advanced development of technology during the last five decades, the fourth generation of Landsat is composed of two similar sensors with very high spectral and radiometric sensitivities: OLI-1 and OLI-2 (Markham et al., 2016; Li and Chen, 2020). The OLI-1 carried onboard Landsat- 8 was launched on $11^{\text {th }}$ February, 2013. While the OLI- 2 will be onboard the Landsat-9 mission which is currently scheduled to launch in September 2021 (NASA, 2019 and 2021). The OLI sensors collect land-surface reflectivity in the VNIR, SWIR, and panchromatic wavelength with a FOV of $15^{\circ}$ covering a swath of $185 \mathrm{~km}$ with 16 days' time repetition at the equator. The band passes are narrower to minimize atmospheric absorption features (NASA, 2014), especially the NIR spectral band $(0.865 \mu \mathrm{m})$. Two new spectral bands have been added: a deep blue visible shorter wavelength (band 1: $0.433-0.453 \mu \mathrm{m}$ ) designed specifically for water resources and coastal zone investigation and a new SWIR band (9: $1.360-1.390 \mu \mathrm{m}$ ) for the detection of cirrus clouds. Moreover, compared to previous TM and ETM+ sensors using only 8 bit, the OLI design results in more sensitive instruments with a significant improvement of the SNR radiometric performance quantized over a 12-bit dynamic range (Level 1 data), and raw data are delivered in 16 bit. The high performance of SNR associated with improved radiometric and spectral resolutions provide a superior dynamic range of radiance by reducing saturation problems and, therefore, enabling better characterization of land and water surface conditions (Knight and Kvaran, 2014), especially with orbit reflective radiometric calibration better than 3\% (Markham et al., 2014; Gascon et al., 2017). Table 1 summarizes the effective bandwidth characteristics of OLI-1 and OLI-2 sensors. 
Otherwise, the Sentinel-2 mission is the result of close collaboration between the European Space Agency, the European Commission, industry, service providers, and data users. It is composed of two satellites, Sentinel-2A which was launched in June 2015, and Sentinel-2B that was launched in March 2017. Both satellites are equipped with identical MSI sensors to provide continuity to the SPOT missions and to improve the Landsat-OLI temporal frequency (Drusch et al., 2012). The synergy between the four sensors (MSI-2A, MSI-2B, OLI-1, and OLI-2) significantly increase the temporal resolution (around 2 days) offering new opportunities for several environmental and natural resource applications, such as the vigour of vegetation cover, emergency management, water quality, seagrass meadows, and climate change impacts analysis at local, regional, and global scales. The MSI images the Earth's surface reflectivity with a large FOV $\left(20.6^{\circ}\right)$ in 13 spectral bands with several spatial resolutions from 10 to 60 -m; four bands with 10-m (blue, green, red, and NIR-1), six bands with 20-m (Red-Edge, NIR-2, and SWIR), and three bands with 60-m (coastal, water vapor and cirrus). The swath of each scene is $290 \mathrm{~km}$, permitting global coverage of the Earth's surface every 10 days. The MSI radiometric performance is coded in 12 bits, ensuring radiometric calibration accuracy of better than 3\% and an excellent SNR (Markham et al., 2014; Li et al., 2017). Table 1 summarizes the effective bandwidth characteristics of MSI-2A and MSI-2B sensors.

As discussed above, the measured bidirectional reflectance factors with the ASD have a 1-nm interval allowing the acquisition of 2151 contiguous hyperspectral bands per spectrum. However, most multispectral remote sensing instruments measure integrated reflectance over broad bands (equation 1). Consequently, the average of 40 spectra measured with the ASD over each sample was resampled and convolved to match the solar-reflective spectral responses functions characterizing the optics and electronics of MSI and OLI instruments in the VNIR spectral bands (Fig. 6). In this step, the resampling procedure considers the nominal width of each spectral band (Table 1). Then, the convolution process was executed using the CAM5S transfer radiative code (Teillet and Santer, 1991). This fundamental step simulates the signal received by the considered sensors at the top of the atmosphere from a surface reflecting solar and sky irradiance at sea level, considering the filter of each band (Fig. 6), and assuming ideal atmospheric conditions without scattering or absorption (Zhang and Roy, 2016). Accordingly, the equivalent convolved reflectance $\left(\rho\left(\lambda_{i}, \lambda_{s}\right) i\right)$ over each sample was generated at the satellite orbit altitude in homologous VNIR spectral bands of each sensor (Slater, 1980):

$\rho\left(\lambda_{i}, \lambda_{s}\right)_{i}=\frac{\int_{\lambda_{i}}^{\lambda_{s}} R(\lambda) . S(\lambda) i . d(\lambda)}{\int_{\lambda_{i}}^{\lambda_{s}} S(\lambda) i . d(\lambda)}$

Where $\rho\left(\lambda_{i}, \lambda_{s}\right) i$ is the equivalent convolved reflectance of the band "i" of each sensor, $\lambda_{\mathrm{i}}$ to $\lambda_{\mathrm{s}}$ are the spectral wavelength ranges of the band " $\mathrm{i}$ " of each sensor, $\mathrm{R}(\lambda)$ is the corresponding reflectance at wavelength " $\lambda$ " measured by the ASD, and $S(\lambda)$ i is the corresponding spectral responsivity value of the spectral response function of the band "i" of each sensor (Fig. 6). It is important to note that the MSI-NIR-2 broadband (band-8: $785-900 \mathrm{~nm}$ ) is not considered in this study because it is not a real homologous band of OLI-NIR, and it has a greatest reflective band 

difference with the OLI-NIR ( $851-879 \mathrm{~nm}$ ). The OLI-NIR spectral response function intersects with only $20 \%$ of the MSI-NIR-2 response function. Moreover, the MSI red-edge bands were not considered also as they are not acquired by the OLI sensor.

[ Figure 6]

\subsection{Data Processing}

In addition to remote sensing sensor technologies' improvement and innovation, a variety of processing methods have been applied for spectral data for mapping and monitoring seagrass and habitats in shallow coastal waters. They were applied to highlight the seagrass and algae species composition, leaf area index estimation, percentage cover mapping, etc. They include matched filtering approach (Li et al., 2012), object-based image analysis (Roelfsema et al., 2014), adaptive coherence estimator and constrained energy minimization ( $\mathrm{Li}$ et al., 2012), artificial neural network model (Ressom et al., 2003; Perez et al., 2020), linear spectral mixture analysis (Uhrin and Townsend, 2016; Chen et al., 2016), spectral angle mapper (Peneva et al., 2008; Li et al., 2012; Marcello et al., 2018; Wicaksono et al., 2019), classification tree analysis (Wicaksono et al., 2019), random forest (Bayyana et al., 2020), support vector machines (Marcello et al., 2018; Bakirman and Gumusay, 2020; Perez et al., 2020; Bayyana et al., 2020), and machine learning regression (Traganos, 2020; Bakirman and Gumusay, 2020). Undeniably, these sophisticated and complicated methods require extensive training information and field endmember measurements. However, the simplicity of empirical and semi-empirical methods based on vegetation indices are easier to transfer between sensors and can be used as a robust alternative compared to the complex processing methods; because these methods are based on the knowledge of spectral absorption features that characterize specifically the target under investigation. Moreover, these methods have the advantage of being reproducible, easily transferable, and applicable in other geographic regions. Each method has advantages and limitations, especially in shallow water. In this study, after the spectral analysis and CRRS transformation, the capability and comparison of the VNIR homologous spectral bands of MSI and OLI sensors were investigated for seawater, sediments, seagrass, algae, and mixed species discrimination at different coverage rates. Then, although the literature refers to more than fifty vegetation indices for land vegetation cover monitoring and characterization (Bannari et al., 1995), only the most popular indices that have been used for seagrass and SAV in different marine environments around the world were retained in this study. After spectral data pre-processing, sampling, and convolving, the indices TGI, VARI, and $\operatorname{Diff}(\mathrm{G}-\mathrm{B})$ were implemented and tested respecting their original and unchangeable equations. While the NDVI, SAVI, EVI, TDVI, NDWI, and DVI indices were calculated in three versions by integrating the red, blue, and green bands. The equations of the considered indices are as follow:

$$
\begin{array}{ll}
\mathrm{NDVI}=\left(\rho_{\mathrm{NIR}}-\rho_{\text {Red }}\right) /\left(\rho_{\text {NIR }}+\rho_{\text {Red }}\right) & \text { (Rouse et al., 1974) } \\
\mathrm{SAVI}=1.5 *\left(\rho_{\mathrm{NIR}}-\rho_{\text {Red }}\right) /\left(\rho_{\text {NIR }}+\rho_{\text {Red }}+0.5\right) & \text { (Huete, 1988) } \\
\mathrm{TDVI}=1.5 *\left(\rho_{\mathrm{NIR}}-\rho_{\text {Red }}\right) /\left(\sqrt{\left(\rho_{\text {NIR }}^{2}+\rho_{\text {Red }}+0.5\right)}\right) & (\text { Bannari et al., 2002) } \\
\mathrm{NDWI}=\left(\rho_{\mathrm{Green}}-\rho_{\text {NIR }}\right) /\left(\rho_{\text {Green }}+\rho_{\text {NIR }}\right) & (\text { McFeeters, 1996) } \\
\mathrm{EVI}=2.5 *\left(\rho_{\mathrm{NIR}}-\rho_{\text {Red }}\right) /\left(\rho_{\text {NIR }}+6 * \rho_{\text {Red }}-7.5 * \rho_{\text {Blue }}+1\right)(\text { Huete et al., 2002) }
\end{array}
$$


$\mathrm{DVI}=\rho_{\mathrm{NIR}}-\rho_{\mathrm{Red}}$

$\operatorname{VARI}=\left(\rho_{\text {Green }}-\rho_{\text {Red }}\right) /\left(\rho_{\text {Green }}+\rho_{\text {Red }}-\rho_{\text {Blue }}\right)$

$\mathrm{TGI}=\rho_{\text {Green }}-0.39 * \rho_{\text {Red }}-0.61 * \rho_{\text {Blue }}$

$\operatorname{Diff}(G-B)=\rho_{\text {Blue }}-\rho_{\text {Green }}$
(Richardson and Wiegand, 1977)

(Gitelson et al., 2002a)

(Hunt et al., 2013)

(Mumby et al., 1997)

\subsection{Statistical analyses}

As discussed previously, the MSI and OLI relative spectral response profiles characterizing the filters of each spectral band are relatively different (Fig. 6). To examine the impact of this difference, statistical analyses were computed using "Statistica" software. The relationships between the product values (reflectances and WVI's) derived from MSI against those obtained from OLI were analyzed between homologous bands using a linear regression model $(\mathrm{p}<0.05)$. As well, the $\mathrm{R}^{2}$ was used to evaluate the strength of this linear relationship. For this process, the resampled and convolved spectra of all samples' reflectance data were used, and the homologous values in VNIR bands of MSI and OLI were compared using the 1:1 line. Ideally, these independent variable values should have a correspondence of 1:1. Additionally, the root mean square difference (RMSD) between both sensors was derived (Willmott, 1982; Zhang et al., 2018):

$\operatorname{RMSD}=\sqrt{\frac{\sum_{i}^{n}\left(v_{i}^{O L I}-v_{i}^{M S I}\right)^{2}}{n}}$

Where RMSD between corresponding Landsat-OLI and Sentinel-MSI variables values (reflectances and WVI's), “ $v_{\mathrm{i}}$ " is the variable under analysis and " $i$ " is the number of variable ( $\mathrm{i}=1$ to $n$ ).

\section{Results analysis}

\subsection{Spectral and CRRS analysis}

Spectral signatures of seagrass and algae species are measured separately and mixed in black and yellow large bowls using two sedimentary substrates (dark and bright). They are presented separately for the examined coverage rates, namely 10,30,75, and 100\% (Fig. 7, a-d). Overall, the reflectance signatures of seagrass and algae samples are similar to those of healthy vegetation canopy. These reflectance signatures exhibit slight absorption features near $450 \mathrm{~nm}$ and others stronger between 650 and $700 \mathrm{~nm}$ with a minimum at $670 \mathrm{~nm}$ caused by the chlorophyll; as well as a significant reflection between 520 and $600 \mathrm{~nm}$ due to carotenoid pigments and high reflectance in the NIR attributed to internal tissue structure (700 to $900 \mathrm{~nm}$ ). Differently to land vegetation, the red-edge is not well developed (very weak) particularly for non-dense seagrass and algae due to high red and NIR absorption by water molecules as shown in Fig. 1. Generally, absorption or reflection of pigmentations between species occurs in different wavelengths but the strength of absorption gradually increases in the red as the coverage rate increases.

For scattered and low coverage $(\sim 10 \%)$, the shapes of all spectra are relatively similar, without the possibility to identify specific absorption features or to separate among species according to their spectra in the visible domain (Fig. 
501 7a). The highest reflectance values vary between $10 \%$ and $15 \%$ across NIR wavelengths with a difference reflectance $\left(\Delta \rho_{\mathrm{NIR}}\right)$ around $5 \%$, while in the visible all the reflectance values are below $5 \%$ with $\Delta \rho_{\text {visible }}$ are also $<5 \%$. For this low and sparse cover, it is observed that the reflectance is influenced by spectral properties of the underlying sediments, fragments of vegetation, light shading, etc., thus contributing to the confusion between spectral signatures. Definitely, under such conditions, it is a challenge to distinguish between seagrass and/or algae species based only on their spectral signatures. Whereas, the measurements acquired over somewhat denser coverage rates $(\sim 30 \%)$ show analogous spectral behaviour and patterns with overlap among spectra in visible wavelengths (400 to $700 \mathrm{~nm}$ ), but a slight separability between species stands out relatively in NIR (Fig. 7b).

Furthermore, unlike scattered or less dense cover $(\leq 30 \%)$, the analysis of the dense and very dense coverage rates (75 and 100\%) showed that the optical properties (darkness or brightness) of the underlying substrate does not have a significant effect on the measured spectra. For these coverage ranges, the clear and normal behaviour of vegetation cover spectra are observed. The absorption feature is weak in the blue (450-480 nm) but more accentuated in red (670 $\mathrm{nm})$, the reflection peak is more highlighted in green $(550 \mathrm{~nm})$, and the reflectance values increase notably and gradually in NIR with the increase of the coverage rate. Although the seagrass has a distinct spectral response compared to the algae, especially in the green and NIR regions of the spectrum, significant spectral differences are noted for the HU with the highest reflectance, followed by GA, HS, and BA. This order is probably controlled by the leaves structures that are specific for each type of seagrass or algae. The reflectance values in the visible are controlled by the absorption of chlorophyll pigmentations in blue and red wavelengths, and by the carotenoid pigmentations in the green band. In addition, compared to HS and BA spectra, HU and GA showed relatively strong absorption by chlorophyll in red wavelengths. This difference is due to the nature of chlorophyll in each species. Indeed, brown algae contain accessory pigments "fucoxanthin" and chlorophyll "c" (Johnsen and Sakshaug, 2007), while seagrass are flowering plants, and their leaves contain chlorophyll "b" (Cummings and Zimmerman, 2003). It is observed also that the BA carotenoid pigments (fucoxanthin) are characterized by spectral features at 630 and $650 \mathrm{~nm}$ that are not present in the spectra of HS, HU, and GA (Fig. 7). However, despite all these spectral characteristics the difference in reflectance values among all species (individual and mixed) is $\leq 6 \%$ in the visible and $\leq 13 \%$ in NIR for a very dense cover (100\%). Therefore, these results suggest that it is probably possible for the blue, green, and NIR wavelengths to discriminate among the considered seagrass and algae species if they are homogeneous with high or very high densities.

Otherwise, the CRRS transformations are presented in Fig. 7 (e-h) with Sentinel-MSI relative spectral response profiles characterizing the filters of VNIR bands. The lower CRRS values indicate the greatest potential spectral separability, which means the identification of the appropriate wavelengths to discriminate among the considered classes of investigated species. As shown in Fig. 7 (e-h), the CRRS significantly enhances the spectral separability among the seagrass and algae classes, especially in the visible bands. Two main absorption features are highlighted in the blue $(485-498 \mathrm{~nm})$ and red $(\sim 670 \mathrm{~nm})$ regardless the species. In the green, one major reflection peak is observed around $544 \mathrm{~nm}$ for $\mathrm{HU}$ and GA, one around $530 \mathrm{~nm}$ for HS, and three peaks are well distinguished for BA at 578, 595, and $640 \mathrm{~nm}$ (Fig. 7h). These differentiation features become clearer as the coverage rates increase especially in blue and NIR wavelengths. For a low coverage rate $(\sim 10 \%)$, the strongest absorption depth is that of GA $(0.46)$ 
followed by HU (0.58), HS (0.74), and BA (0.78) in the blue (Fig. 7e). While in the red, CRRS pointed out that regardless of the coverage rate, a strong similarity is observed between $\mathrm{HU}$ and GA due to their high content of chlorophyll pigmentation with a depth of absorption around 0.29. Subsequently followed by HS and BA that are characterized by less absorption depth $(\sim 0.50)$. In these two waveband domains (blue and red), the absorption features become deeper with increasing coverage density. Likewise, when the cover rate of all species becomes denser (100\%), similar absorption characteristics are exhibited in the red band between HU and GA species; as well as between HS and BA (Fig. 7h). While in the blue and NIR wavelengths, the CRRS highlights the distinction and differentiation between species. On the other hand, as the coverage increases from 10 to $100 \%$, the reflection peak in the green waveband becomes less pronounced due to the high content of carotenoid pigment; also a strong similarity is observed between HU and GA. Moreover, the curves of CRRS of the mixed species occupy an intermediate position of absorption features between the homogeneous samples and, therefore, the differentiation between absorption characteristics becomes very narrow. Accordingly, the discrimination between pure and mixed species becomes very difficult or even impossible. Overall, spectral and CRRS analyses highlighted the importance of the blue, green, and NIR wavelengths for seagrass and algae detection and probable discrimination based on hyperspectral measurements. These results corroborate the physical concept presented in Fig. 1 that the blue and green electromagnetic radiation penetrates a deeper vertical column of water. While despite its limited penetration, the NIR shows a certain sensitivity to the biomass density and its spatial distribution.

[ Figure 7]

\subsection{Resampling and convolving in OLI and MSI bands}

Fig. 8 illustrates the scatter-plots between the resampled and convolved reflectance values in the VNIR homologous bands of the MSI and OLI sensors. Simulated at the top of the atmosphere using all considered samples (seawater, sediments, seagrass, algae and mixed species of both seagrass and algae at unlike coverage rates), they allow the analysis of the difference in reflectance values $(\Delta \rho)$ and RMSD due exclusively to dissimilarities in spectral response function between homologous bands. These scatter-plots reveal a near-perfect fit with 1:1 line expressing an excellent coefficient of determination ( $\mathrm{R}^{2}$ of 0.999$)$ between homologous bands with the slopes and intercepts very near to unity and zero, respectively. Thus, the derived $\Delta \rho$ values are null for VNIR homologous bands for seawater and are insignificant for dark and bright substrate sediments in all bands (i.e., 0.009 for green and 0.002 for the coastal, blue, red, and NIR bands). While, for seagrass and algae (HS, HU, GA, and BA), $\Delta \rho$ vary between 0.003 and 0.02 regardless of the coverage rate or the considered spectral band. Moreover, the achieved overall RMSD in reflectance between MSI and OLI homologous bands considering all samples are insignificant $(\leq 0.0015)$ for blue, green, and red bands, and null for coastal and NIR bands. It is also observed that all the bands are insensitive to the variation of the colors of the bowls and the sedimentary substrate optical properties. These results pointed out that MSI and OLI sensors are spectrally similar and can be used jointly for high temporal frequency to monitor seagrass and algae dynamics in time 
and space. Therefore, due to this near-perfect spectral similarity between these instruments, our analysis in the following sections will focus only on the MSI sensor.

[ Figure 8 ]

Fig. 9 illustrates the reflectances of seagrass, algae, and seawater resampled and convolved in VNIR bands of MSI or OLI sensors considering each species separately and all species at different coverage rates. Compared to the measured hyperspectral signatures (Fig. 7), these broadband spectra are more generalized and less precise because these spectra lost the specific and unique absorption features of seagrass and/or algae species caused by pigmentations as discussed above. However, such broadband spectra still retain the same spectral pattern as the original spectra. Regardless of the species, the graphics summarized in Fig. 9 exhibit similar shape and pattern, but with a slight difference in reflectance values between species in the visible bands. If we consider the species separately (HS, HU, GA, and BA) in different coverage rates $(10,25,75$, and $100 \%)$, the reflectance difference values $(\Delta \rho)$ are $\leq 0.02$; and insignificant $(\Delta \rho \leq 0.002)$ for pure seawater and sediments in all VNIR bands. Hence, these species are not spectrally distinguishable particularly in the visible whatever the coverage. While, if we consider all samples (seagrass, algae, and mixed) in all coverage rates (Fig. 9e), the $\Delta \rho$ are equal to 0.03 in coastal and blue bands, 0.05 in green, 0.035 in red and 0.21 in NIR. Except for the NIR, the calculated $\Delta \rho$ values in the visible are approximately identical to the accuracies achieved from radiometric calibration and atmospheric corrections. Therefore, relying on the multispectral bandwidth of OLI and MSI sensors, it is difficult or even impossible to differentiate or to map seagrass and algae individually at the species level. Accordingly, SAV classes' discrimination and mapping will be discussed.

[ Figure 9]

\subsection{Vegetation indices analysis}

In this third part, the NDVI, SAVI, EVI, TDVI, NDWI, and DVI indices were implemented and analysed in three versions each by integrating the red, blue, and green bands; while the indices TGI, VARI, and Diff(G-B) were calculated and tested respecting their original and unchangeable equations. In total, 21 combinations of indices were calculated for each sensor. The statistical analyses $(\mathrm{p}<0.05)$ focus on the similarity or dissimilarity between MSI and OLI homologous indices, and their potential for seagrass and algae discrimination. Except for the TGI and VARI indices, the results revealed an excellent linear relationship ( $\mathrm{R}^{2}$ of 0.999$)$ between MSI and OLI products regardless of the compared index and the integrated spectral bands (red, green, and blue). Overall, the scatter-plots presented in Fig. 10 depict a very good fit to the 1:1 line with the slopes and intercepts very near to unity and zero, respectively. However, despite its near-perfect linearity and insignificant RMSD between MSI and OLI values (0.001), the TGI show a very weak and limited spatial variability with a range between 0 for pure seawater and 0.05 for a very dense coverage $(100 \%)$ of seagrass or algae (Fig. 10e). This range cannot allow the differentiation among the marine environment classes, because this index was not developed for biomass sensing but was designed for crop nitrogen requirements detection. Likewise, although the scatter-plot of VARI shows an excellent coefficient of determination 
609 ( $\mathrm{R}^{2}$ of 0.99$)$, this index overestimates the predicted values by MSI sensor compared to those estimated by OLI, resulting in the data not fitting the 1:1 line very well (Fig. 10f). Moreover, the difference values of VARI derived from MSI and OLI data vary between 0 and 0.14 depending on the sample species and its coverage rate, with an overall RMSD of 0.03 . This result can be explained by the fact that the VARI uses only the visible ranges of the spectrum and does not consider the NIR band which is the most informative about the biomass density. In addition, it was developed particularly for very dense (100\%) wheat crops; moreover, it was designed principally for coarse data acquired by the SeaWiFS, MODIS, MISR, and MERIS sensors. According to Gitelson et al. (2002b), many factors potentially decrease the accuracy of the VARI such as vegetation cover species, canopy architecture, and sun illumination geometry. For wheat and corn species, this index yielded RMSE of around 10\% (Gitelson et al., 2002a). Therefore, the weaknesses raised for these two indices (TGI and VARI) are not caused by the impact due exclusively to the dissimilarities in spectral response function between homologous bands of MSI and OLI sensors, but due to their mathematical concepts that are intended for a single and specific application.

Furthermore, the scatter-plots presented in Fig. 10 (a-d) are showing examples of certain indices including NDWI, WAVI, WEVI, and WTDVI. Overall, the indices are fitting very well the $1: 1$ line with $\mathrm{R}^{2}$ of 0.99 , slopes very near to unity and intercepts to zero. The indices show that the derived WVI from MSI and OLI data are predicting similarly seagrass and algae species in a shallow marine environment. Considering all investigated samples in this study, the interval difference values between homologous indices vary between 0 and 0.01 for all versions of WTDVI, WAVI, WDVI, and Diff(G-B); while they vary between 0 and 0.04 for NDWI, WEVI and NDWI. These differences values are satisfactory and remain equal or less than the combined inaccuracies of atmospheric corrections and sensor radiometric calibration. Moreover, the achieved RMSD values between MSI and OLI homologous indices are insignificant $(\mathrm{RMSD} \leq 0.01)$ for all indices (Table 2) regardless of the integrated spectral band. These analyses pointed out that MSI and OLI sensors can be combined for high temporal frequency to monitor the dynamic of biophysical products in time and space in a shallow marine environment.

\section{[ Table 2 ]}

[ Figure 10]

Fig. 11 summarises the linear regressions $(\mathrm{p}<0.05)$ between the best indices and the reflectances in NIR considering all samples, i.e., seawater, sediments, seagrass, algae, and mixed species classes with different coverage rates (10, 30, 75, and 100\%). The computed indices (NDVI, SAVI, EVI, TDVI, NDWI, and DVI) with the blue, green, and red bands are the most relevant for SAV differentiation and mapping. Firstly, it is observed that the indices NDVI and NDWI provided similar results with opposite signs, i.e., symmetrically opposed concerning the X-axis. Indeed, whatever the integrated band, the NDWI results are always symmetrical compared to those of NDVI but with negative values. However, such results are not showing the truth because negative values are automatically reset to zero by the image processing system and, therefore, it is probable that the results will be inaccurate. Furthermore, when the red and blue bands are implemented in the NDVI equation, insignificant fits $\left(\mathrm{R}^{2}\right.$ of 0.40$)$ were achieved; but improved 
results are obtained with the integration of the green band $\left(\mathrm{R}^{2}\right.$ of 0.63$)$ and the index is named NDWVI. Analogous results are obtained by Diff(G-B) and VARI indices with $\mathrm{R}^{2}$ of 0.63 (Table 2) when all samples are considered. Luckily, the statistical fits of these three indices (NDWVI, Diff(G-B), and VARI) becomes significantly improved when unique species is considered, such as only seagrass or only algae $\left(\mathrm{R}^{2}\right.$ of 0.85$)$. Whereas, in addition to its weakness and limited sensitivity to the spatial variability of seagrass and algae, the TGI was irrelevant for SAV discrimination yielding a very low fits $\left(\mathrm{R}^{2}\right.$ of 0.20$)$ whatever the considered species.

\section{[ Figure 11]}

As discussed previously, when integrating the blue and green bands, the indices WDVI, WAVI, WEVI, and WTDVI outperformed all examined indices regardless of the species (seagrass, algae, or mixed), yielding a very significant coefficient of determination for mixed species $\left(0.89 \leq \mathrm{R}^{2} \leq 0.96\right)$ (Fig. 11 a-d, and Table 2). Calculated with blue, green, or red bands, the DVI (noted WDVI) discriminated among SAV classes significantly $\left(\mathrm{R}^{2} \leq 0.92\right)$, but it underestimates the SAV as shown in Fig. 10-d. However, WAVI, WEVI, and WTDVI offer similar trends regardless the considered species $\left(\mathrm{R}^{2} \leq 0.92\right.$ for mixed or seagrass only, and $\mathrm{R}^{2}$ of 0.82 for algae only). Overall, instead of the red band, the integration of blue and green bands in vegetation indices increases their discriminating power for SAV (Table 2). These results corroborate the spectral analysis and the CRRS transformations; the blue and green electromagnetic radiation penetrates deeper through the water allowing more details and information about marine vegetation discrimination. This finding is consistent with Wicaksono and Hafizt (2013), and Villa et al. (2014) where the blue band better separates and maps aquatic vegetation features over some lake ecosystems in Italy. However, the summarized $\mathrm{R}^{2}$ in Table 2 shows that the indices WAVI, WEVI, and WTDVI provided relatively identical results when integrating the blue or green bands. Nevertheless, the scatter plots in Fig. 11 (a, b, and c) illustrate that when the green band is considered instead of the blue, the majority of sampled points are located closer to line 1:1, especially when the coverage rate becomes denser. This can be explained by the fact that despite the power of blue wavelengths to penetrate deeper into the water, this band also leads to an overestimation of indices values due to its higher scattering (Fig. 11), mainly in turbid environments.

\section{Discussion}

Seagrass and algae species showed similar spectral signature curves, but with subtle differences between species. In general, some relevant wavelengths are observed for the characterization of the considered species of seagrass and algae including those at or near 450, 500, 520, 550, 600, 620,640, 670, and $700 \mathrm{~nm}$. They are related to the absorption features and reflection peaks due to photosynthetic pigmentations of HU, HS, GA, and BA. Spectral and CRRS analyses highlighted the importance of the blue, green, and NIR wavelengths for probable differentiation between the considered seagrass and algae types. However, the magnitude of the $\Delta \rho$ values among species is an indicator of the strength of the absorption feature depths and, therefore, of their discriminating power between species. For instance, the highest $\Delta \rho$ values among all considered samples (seagrass, algae, and mixed of both) is $\leq 5 \%$ across the visible wavelengths and around 10 to $15 \%$ in NIR. Likewise, the CRRS transformations of all spectra of homogeneous and 
mixed samples show that the absorption characteristics become very narrow and, thus, the discrimination between pure and mixed species becomes difficult or even impossible. These results are in agreement with other findings that have been conducted in many geographic locations worldwide and have considered many seagrass and algae types. Considering nine tropical species of seagrass, Wicaksono et al. (2019) showed that even hyperspectral data will not improve discrimination between seagrass and algae at the species level in pixels or sub-pixels due to the subtle difference in absorption features among them. As well, Phinn et al. (2008) confirmed that the hyperspectral data are unable to map seagrass biomass at the species level in shallow waters of Moreton Bay in Australia. Using field and laboratory hyperspectral measurements over several seagrass species on the west coast of Florida, Pu et al. (2012) reported also that the VNIR wavelengths have relatively low accuracies to discriminate among seagrass community composition.

Otherwise, the resampled and convolved spectra in VNIR bands of MSI and OLI sensors are similar in all cases, considering each species separately or the totality of samples at different coverage rates. These spectra are more generalized and less precise due to the loss of absorption features caused by pigmentations. Hence, regardless of the coverage rates, if the pure and homogenize species are considered, the $\Delta \rho$ is $\leq 0.02$ in the visible and is $\leq 0.22$ in NIR. While, if all mixed samples and species are considered at the investigated coverage rates, $\Delta \rho$ is $\leq 0.05$ in visible bands and remains stable $(\Delta \rho \leq 0.22)$ in NIR. These very narrow values do not allow spectral distinction among species, particularly in the visible wavebands. Therefore, relying on the multispectral bandwidth of OLI and MSI sensors, it is difficult to differentiate seagrass and algae individually at the species level. Indeed, it is important to remember that these simulations were conducted in a Goniometric-Laboratory using close range measurements protocol and supervising rigorously all measured samples, i.e., homogeneous, or mixed. Moreover, in this controlled environment, the atmospheric scattering and absorption are absent; errors related to the sensor radiometric calibration are also absent, no wave's variation, no residual clouds contamination, no sun-glint (specular effects), no variability in water depth, and no BRDF impact. However, the results obtained are not entirely conclusive and do not provide a clear and satisfactory distinction among the spectral signatures of the investigated species. The difference among spectral signatures is surely reduced in the real world when seagrasses and algae are embedded in sediments and overlaid by water column and constituents including phytoplankton, suspended organic and inorganic matter, variability in water depth, and remote sensing problems (internal and external). Additionally, the acquired images with Sentinel-MSI (2A and 2B) and Landsat-OLI (8 and 9) sensors are coded radiometrically in 12 and 16 bits, respectively. These images cover dissimilar pixels surfaces of $100 \mathrm{~m}^{2}$ for MSI and $900 \mathrm{~m}^{2}$ for OLI, where SAV information can be easily mixed within pixels. Besides, the FOV of these instruments are different, OLI's FOV is $15^{\circ}$ covering a swath of $185 \mathrm{~km}$, while the MSI is characterized by a large FOV of $20.6^{\circ}$ covering a swath of $290 \mathrm{~km}$, which requires the adjustments to reduce differences caused by BRDF effects (acquisition and sun illumination geometries). Data quality may also change due to the sensor's radiometric performance, SNR, and atmospheric interferences (diffusion and absorption). Nevertheless, despite the corrections of all these anomalies before the information extraction, biases still occur generated by errors propagation, which affect the recorded signal at the sensor level and, therefore, the precision of discrimination between seagrass and algae at the species level. For instance, if we consider the published RMSE regarding each source of error separately, the calculated total RMSE based on errors propagation theory (equation 12) 
will be approximately 0.08 to 0.10 (reflectance unit). Therefore, this total RMSE is greater than the achieved difference between reflectance values $(\Delta \rho \leq 0.05)$, especially in the visible bands. Accordingly, it is impossible to differentiate between seagrass and algae at the species level. Likewise, this total RMSE is solely due to the I imitations of remote sensing methods, but it can also be amplified by environmental restrictions of seagrass habitat, as discussed above and reported by Wicaksono and Hafizt (2013).

RMSE-Total $=\left[(\sigma \text {-Sensor-drift })^{2}+(\sigma \text {-Atmosphere })^{2}+(\sigma \text {-Sun-glint })^{2}+(\sigma \text {-BRDF })^{2}+(\sigma \text {-Water-column })^{2}\right]^{0.5}$

\section{Where:}

$\sigma$-Sensor-drift: Sensor radiometric calibration accuracy, \pm 0.03 (Markhman et al., 2014 and 2016),

$\sigma$-Atmosphere: Atmospheric corrections accuracy, mostly around \pm 0.03 to \pm 0.05 in the visible bands (Vermote et al., 2016),

$\sigma$-Sun-glint: Sun glint correction accuracy, \pm 0.05 (Zorrilla et al., 2019),

$\sigma$-BRDF: Accuracy of BRDF correction for MSI, \pm 0.05 to \pm 0.08 (Roy et al., 2017),

$\sigma$-water-column: Accuracy of water column correction, \pm 0.04 (Zoffoli et al., 2014).

The results of this research accomplished in the Arabian Gulf species based on spectroradiometric measurements are consistent with other researches carried out in many geographical regions worldwide. Barillé et al. (2009) showed the degradation of spectral features when resampled into SPOT-HRV visible bands and, therefore, seagrass species could no longer be discriminated in these wavelengths. This statement is also in agreement with Wicaksono et al. (2017) who reported that resampled spectra in MSI and OLI bands do not have sufficient spectral information for seagrass species discrimination for accurate classification. Moreover, it was reported that sub-pixel species composition and mixing added complexity to seagrass species mapping even using hyperspectral data and advanced image processing approaches (Phinn et al., 2008; Joyce et al., 2013; Hedley et al., 2012a and 2012b). For instance, Wicaksono et al. (2019) highlighted the limitation of SAM for seagrass mapping due to the similarity of absorption features among the spectral signatures of the mapped seagrass species. As well, Chen et al. (2016) revealed the difficulty and limitation of LSMA for mapping scattered and heterogeneous seagrass patches that are smaller than the pixel size due to spectral confusion between the seagrass and other SAV classes. Using MSI and OLI data with respectively $10 \mathrm{~m}$ and $30 \mathrm{~m}$ pixel sizes (i.e., each OLI pixel is represented by 9 MSI pixels), Lyons et al. (2011) reported relatively accurate discrimination between seagrass meadows spots that are very large with homogenous composition and distinct boundaries between species. However, if the analyzed patches are heterogeneous, composed of diverse species and scattered without clear boundary, then the differentiation becomes impossible. Therefore, SAV classes' discrimination and mapping need to be thoroughly adopted to be able to map seagrass and algae on species level rather than relying on the multispectral bandwidth of OLI and MSI sensors.

Furthermore, to analyze the impact of differences in reflectance exclusively due to dissimilarities in spectral response function between homologous spectral bands, the scatter-plots between SMI and OLI simulated surface 
reflectance values at the top of the atmosphere revealed a very good linear relationship ( $\mathrm{R}^{2}$ of 0.999$)$ between VNIR homologous bands. The slopes and intercepts are nearly equal to unity and zero, respectively. It is also observed that independently to the sediments substrate (dark and bright) or the color of used bowls (black or yellow), the $\Delta \rho$ values between VNIR homologous bands vary in the range of 0.003 to 0.02 , regardless of the observed species (seagrass, algae and mixed) or the coverage rate. Moreover, the achieved overall RMSD in reflectance values are very small $(\leq$ $0.0015)$ for all VNIR bands, i.e., smaller than the uncertainty of the radiometric calibration process $(0.03)$ as demonstrated by Markham et al. (2016). In other respect, all the derived homologous WVI values fit near-perfectly with the 1:1 line expressing an excellent coefficient of determination $\left(\mathrm{R}^{2}\right.$ of 0.99$)$, a slope of 0.99 and intercept equal to zero. Moreover, the achieved RMSD values between MSI and OLI homologous indices are insignificant (RMSD $\leq$ 0.01) for all indices regardless of the integrated spectral band (red, green, and blue).

These results corroborate the finding of Wicaksono et al. (2019) who reported that MSI and OLI had similar results for tropical seagrass species analysis using simulated reflectance spectra and imagery data. Moreover, using simulated data and real images acquired simultaneously with MSI and OLI over a wide variety of land cover types including open shallow water, Mandanici and Bitelli (2016) showed a very high coefficient of determination $\left(\mathrm{R}^{2}\right.$ of 0.98$)$ between homologous bands. Comparing surface reflectances and derived biophysical variables over Australian territory, Flood (2017) indicated good compatibility between SMI and OLI instruments with an RMSD < 0.03 for surface reflectance in VNIR bands, and an RMSD around 0.05 for biophysical variables. Pastick et al. (2018) demonstrated that observations made by MSI, and OLI can be used to monitor vegetation phenology accurately in dry lands of the Western United States. In Europe, the comparison of surface reflectances and biophysical products of various natural test sites showed a good relationship between MSI and OLI products, yielding RMSD values around 0.03 reflectance units (Vuolo et al., 2016). Excellent consistency and similarity have also been demonstrated between these sensors for soil observation and modeling in the Middle East (Bahrain) and North Carolina in the USA (Bannari et al., 2020; Davis et al., 2019). Therefore, these results pointed out that the examined sensors, MSI onboard Sentinel2A/2B and OLI onboard Landsat-8/9, can be combined for the marine environment and SAV detection, mapping, and monitoring during shorter time intervals or for consecutive observations. However, rigorous pre-processing issues (sensors calibration, atmospheric corrections, sun-glint corrections, and BRDF normalization) must be addressed before the joint use of acquired data with these sensors. Furthermore, we demonstrated that blue and green bands are better than red for seagrass and algae biomass discrimination, providing the best $\mathrm{R}^{2}$ and the most insignificant RMSD for the investigated indices. Nevertheless, it is preferable to consider the green band integration due to its sensitivity to pigment content within seagrass and algae tissues, for its ability to penetrate water, and for its low sensibility to atmosphere and water column scattering compared to the blue band.

\section{Conclusions}

The MSI sensors onboard Sentinel satellites 2A/2B and the OLI instruments installed on Landsat 8/9 satellites are designed to be similar in the perspective that their data be used together to support global Earth surface reflectances coverage for science and development applications at medium spatial resolution and near-daily temporal resolution. However, relative spectral response profiles characterizing the filter's responsivities of these instruments are not 
identical between the homologous bands, so some differences are probably expected in the recorded shallow water reflectance values for seagrass, algae, and mixed species differentiation and mapping. Based on spectral analysis and CRRS transformation, the results of the present research pointed out subtle spectral differences between seagrass (HU and HS), algae (green and brown), or mixed species, particularly in the blue, green, and NIR wavelengths. However, once resampled and convolved in MSI and OLI homologous VNIR bands, similar patterns to the original spectra are observed but with severe generalisation and loss of specific absorption features. Therefore, mapping seagrass and/or algae at the species level in shallow marine waters is a very difficult if not impossible task, either using multispectral bandwidth of MSI and OLI sensors or even hyperspectral data. Moreover, different from these ideal simulations in a controlled environment, the mapping would be more difficult in a real marine habitat where various species are mixed and interleaved with each other, as well as the propagation of internal and external errors related to remote sensing data. Hence, it is recommended to discuss SAV rather than the mapping seagrass or algae at the species level. Moreover, instead of the red band, the integration of the blue and green bands in WVI increases their discriminating power and ability of map SAV, particularly WAVI, WEVI, and WTDVI indices. These results corroborate the spectral analysis and the CRRS transformations that the blue and green electromagnetic radiation allows better marine vegetation differentiation. Nevertheless, despite the power of blue wavelength to penetrate deeper into the water, it also leads to a relative overestimation of dense SAV coverage due to the higher scattering in this part of the spectrum, particularly in the turbid environment. Furthermore, statistical fits between SMI and OLI simulated surface reflectance over the considered samples reveal an excellent linear relationship ( $R^{2}$ of 0.999) between all homologous VNIR bands. The achieved RMSD values are extremely small between the NIR homologous bands and insignificant for the other bands $(\leq 0.0015)$. Moreover, independently of the analysed samples, homogeneous (seagrass or algae) or mixed (seagrass plus algae), good agreements $\left(0.63 \leq \mathrm{R}^{2} \leq 0.96\right)$ were also obtained between homologous WVI regardless of the integrated spectral bands (i.e., red, green, and blue), yielding insignificant RMSD $(\leq 0.01)$. These achieved RMSD values for reflectances or WVI's are less than the combined errors related to sensor radiometric calibration and atmospheric corrections. Accordingly, these results pointed out that MSI and OLI sensors are spectrally similar and can be combined for high temporal frequency to monitor accurately the SAV and its dynamic in time and space in the shallow marine environment. However, rigorous pre-processing issues such as sensors calibration, atmospheric corrections, BRDF normalisation, sun glint, and water column corrections must be addressed before the joint use of acquired data with these sensors.

7. Author Contributions: Professor A. Bannari performed the paper conceptualization, field data collection, preprocessing and processing, results analyses and paper writing. Professor S.T. Ali assisted in the field sampling, the results analyses and the paper writing. Professor A. Abuhussain assisted in the results interpretation, analyses and paper writing. All authors have read and agreed to the published version of the manuscript.

8. Competing Interests: The authors declare no conflict of interest. 
828

829

830

831

832

833

834

835

836

837

838

839

840

841

842

843

844

845

846

847

848

849

850

851

852

853

854

855

856

857

858

859

860

861

862

863

864

\section{Acknowledgements}

The authors would like to thank the Arabian Gulf University (Kingdom of Bahrain) for the financial support for the field data collection, and to Marine and Environment Arabia Consultancy Services (Manama, Bahrain), for providing photographs and making them available for consultation and public use. Our gratitude goes also to the anonymous reviewers for their constructive comments.

\section{References}

Ackleson, S. G. and Klemas, V.: Remote sensing of submerged aquatic vegetation in lower Chesapeake Bay: A comparison of Landsat MSS to TM imagery. Remote Sensing of Environment, 22(2), 235-248, 1987.

Anders, K. and Lina, N.: Remote sensing of seagrasses in a patchy multi-species environment. International Journal of Remote Sensing, 32(8), 2227 - 2244, 2011.

ASD: Analytical Spectral Devices. Technical Guide, $4^{\text {th }}$ ed.; ASD Inc.: Boulder, CO, USA. Available online: http://www.asdi.com/products-spectroradiometers.asp (accessed on 30 September 2020), 2015.

Bakirman, T. and Gumusay, M. U.: Assessment of Machine Learning Methods for Seagrass Classification in the Mediterranean. Baltic J. Modern Computing, 8(2), 315-326. https://doi.org/10.22364/bjmc.2020.8.2.07 , 2020.

Bannari, A.: Synergy between Sentinel-MSI and Landsat-OLI to Support High Temporal Frequency for Soil Salinity Monitoring in an Arid Landscape. In: Research Developments in Saline Agriculture, edited by Jagdish Chander Dagar, Rajender Kumar Yadav, and Parbodh Chander Sharma. Published by Springer Nature Singapore Pte Ltd., pp. 67-93, ISBN: 978-981-13-5831-9. https://doi.org/10.1007/978-981-13-5832-6_3, 2019.

Bannari, A., Morin, D., Huete, A. R. and Bonn, F.: A Review of Vegetation indices. Remote Sensing Reviews, 13, 95-120, 1995.

Bannari, A., Asalhi, H. and Teillet, P. M.: Transformed Difference Vegetation Index (TDVI) for Vegetation cover Mapping. International Geoscience and Remote Sensing Symposium (IGARSS’2002), Toronto, Ontario, 9-13 July, pp. 3053-3055, 2002.

Bannari, A., Teillet, P. M., and Landry, R.: Comparaison des réflectances des surfaces naturelles dans les bandes spectrales homologues des capteurs TM de Landsat-5 et TME+ de Landsat-7. Revue Télédétection, 4(3), 263-275, 2004.

Bannari, A. and Kadhem, G.: MBES-CARIS Data Validation for Bathymetric Mapping of Shallow Water in the Kingdom of Bahrain on the Arabian Gulf. Remote Sensing, 9, 385-404, 2017.

Bannari, A. and Al-Ali, Z.: Ground Reflectance Factor Retrieval from Landsat (MSS, TM, ETM+, and OLI) Time Series Data based on Semi-empirical Line Approach and Pseudo-invariant Targets in Arid Landscape. International Geoscience and Remote Sensing Symposium (IGARSS-2020), July 19-24 ${ }^{\text {th }}$, Waikoloa, Hawaii, USA, pp. 5990-5993, 2020.

Bannari, A., Hameid, N. Abuelgasim, A. and El-Battay, A.: Sentinel-MSI and Landsat-OLI Data Quality Characterization for High Temporal Frequency Monitoring of Soil Salinity Dynamic in an Arid Landscape. IEEE Journal of Selected Topics in Applied Earth Observations and Remote Sensing (J-STARS), 13(1), 2434-2450, 2020. 
Barillé, L., Mouget, J. L., Méléder, V., Rosa, P., Jesus, B.: Spectral response of benthic diatoms with different sediment backgrounds. Remote Sensing of Environment, 115(4), 1034-1042, 2011.

Barillé, L., Robin, M., Harin, N., Bargain, A. and Launeau, P.: Increase in seagrass distribution at Bourgneuf Bay (France) detected by spatial remote sensing. Aquatic Botany, 92(3), 185-194, 2010.

Bargain, A., Robin, M., Le-Men, E., Huete, A. R. and Barillé, L.: Spectral response of the seagrass Zostera noltii with different sediment backgrounds. Aquatic Botany, 98, 45-56, 2012.

Bayyana, S., Pawar, S., Gole, S., Dudhat, S., Pande, A., Mitra, D., Johnson, J. A. and Sivakumar, K.: Detection and mapping of seagrass meadows at Ritchie's archipelago using Sentinel 2A satellite imagery. Current Science, 118(8), 1275-1282. DOI: 10.18520/cs/v118/i8/1275-1282, 2020.

Ben-Dor, E., Ong, C. and Lau, I. C.: Reflectance measurements of soils in the laboratory: Standards and protocols. Geoderma, 245-246, 112-124, 2015.

Boström, C., Pittman, S., Kneib, R. and Simenstad, C.: Seascape ecology of coastal biogenic habitats: advances, gaps and challenges. Marine Ecology Progress Series, 427, 191-217, 2011.

Burfeind, D. D. and Stunz, G. W.: The effects of boat propeller scarring intensity on nekton abundance in subtropical seagrass meadows. Marine Biology (Berlin), 148, 953-962, 2006.

Candra, E. D., Hartono, and Wicaksono, P.: Above Ground Carbon Stock Estimates of Mangrove Forest Using Worldview-2 Imagery in Teluk Benoa, Bali. IOP Conference Series: Earth and Environmental Science, 47(1). https://doi.org/10.1088/1755-1315/47/1/012014, 2016.

Chen, C.-F., Lau, A.-K., Chang, N.-B., Son, N.-T., Tong, P.-H.-S and Chiang, S.-H.: Multi-temporal change detection of seagrass beds using integrated Landsat TM/ETM+/OLI imageries in Cam Ranh Bay, Vietnam. Ecological Informatics, 35, 43-54, 2016.

Clark, R. N. and Roush, T. L.: Reflectance spectroscopy: Quantitative analysis techniques for remote sensing applications. Journal of Geophysical Research, 89, 6329-6340, 1984.

Clark, R. N., King, T. V. V. and Gorelick, N. S.: Automatic continuum analysis of reflectance spectra. In JPL Proceedings of the $3^{\text {rd }}$ Airborne Imaging Spectrometer Data Analysis Workshop, 138-142. Available on line: https://ntrs.nasa.gov/archive/nasa/casi.ntrs.nasa.gov/19880004388.pdf (accessed on 18 March 2021), 1987.

Clark, R. N., Gallagher, A. J. and Swayze, G. A.: Material absorption-band depth mapping of imaging spectrometer data using the complete band shape least-squares algorithm simultaneously fit to multiple spectral features from multiple materials. In: Proceedings of the Third Airborne Visible/Infrared Imaging Spectrometer (AVIRIS) Workshop, NASA - Jet Propulsion Laboratory Publications, No. 90-54, pp. 176-186, 1990.

Clark, R. N. and Swayze, G. A.: Mapping minerals, amorphous materials, environmental materials, vegetation, water, ice and snow, and other materials. The USGS Tricorder algorithm, in Green, R.O., ed., Summaries of the fifth annual NASA Jet Propulsion Laboratory airborne earth science workshop: Pasadena, NASA Jet Propulsion Laboratory Publication, 95(1), 39-40, 1995.

Clark, R. N., Swayze, G. A., Carlson, R., Grundy, W. and Noll, K.: Spectroscopy from Space. Reviews in Mineralogy and Geochemistry, 78(1), 399-446. DOI:10.2138/rmg.2014.78.10, 2014. 
Crowley, J. K., Brickey, D. W. and Rowan, L. C.: Airborne imaging spectrometer data of the Ruby Mountains, Montana: mineral discrimination using relative absorption band-depth images. Remote Sensing of Environment, 29(2), 121-134. https://doi.org/10.1016/0034-4257(89)90021-7, 1989.

Cummings, M. E. and Zimmerman, R. C.: Light harvesting and the package effect in the seagrasses Thalassia testudinum Banks ex König and Zostera marina L.: Optical constraints on photo-acclimation. Aquatic Botany, 75, 261-274, 2003.

Dahdouh-Guebas, F., Coppejans, E. and Van-Speybroeck, D.: Remote sensing and zonation of seagrasses and algae along the Kenyan coast. Hydrobiologia, 400, 63-73, 1999.

Dattola, L., Rende, S. F., Dominici, R., Lanera, P., Di-Mento, R., Scalise, S., Cappa, P., Oranges, T. and Aramini, G.: Comparison of Sentinel-2 and Landsat-8 OLI satellite images vs. high spatial resolution images (MIVIS and WorldView-2) for mapping Posidonia oceanica meadows. Proceedings of SPIE 10784, Remote Sensing of the Ocean, Sea Ice, Coastal Waters, and Large Water Regions, 10 October 2018, Vol. 10784, 1078419-1; doi: 10.1117/12.2326798, 2018.

Davis, E., Wang, C. and Dow, K.: Comparing Sentinel-2 MSI and Landsat 8 OLI in soil salinity detection: a case study of agricultural lands in coastal North Carolina". Int. J. of Remote Sens., 40(16), 6134-6153. DOI: 10.1080/01431161.2019.1587205, 2019.

Davranche, A., Lefebvre, G. and Poulin, B.: Wetland monitoring using classification trees and SPOT-5 seasonal time series. Remote Sensing of Environment, 114(3), 552-562, 2010.

Dean, A. and Salim, A.: Remote sensing for the sustainable development of offshore mariculture. In: A global assessment of offshore mariculture potential from a spatial perspective, edited by: Kapetsky, J. M., AguilarManjarrez, J. and Jenness, J.: FAO Fisheries and Aquaculture Technical Paper N. 549, Rome, Italy, 181 pp, 2013.

Dekker, A. G., Hestir, E. L., Malthus, T. J. and Thankappan, M.: Continental Scale Aquatic Habitat Monitoring Using Sentinel-2. ESA-ESRIN, Frascati, Italy, 23 to 27 April; 28 pp, 2012

Den-Hartog, C.: The seagrasses of the world. North-Holland Publushing Company, Amsterdame, Netherland, 275 pp. https://doi.org/10.1002/iroh.19710560139, 1970.

Dierssen, H. M., Chlus, A. and Russell, B.: Hyperspectral discrimination of floating mats of seagrass wrack and the macroalgae Sargassum in coastal waters of Greater Florida Bay using airborne remote sensing. Remote Sensing of Environment, 167, 247-258, 2015.

Drusch, M., Del-Bello, U., Carlier, S., Colin, O., Fernandez, V., Gascon, F., Hoersch, B., Isola, C. Laberinti, P., Martimort, P., Meygret, A., Spoto, F., Sy, O., Marchese, F., Bargellini, P.: Sentinel-2: ESA's optical highresolution mission for GMES operational services. Remote Sensing of Environment, 120, 25-36. https://doi.org/10.1016/j.rse.2011.11.026, 2012.

Duarte, C. M. and Gattuso, J.-P.: Seagrass meadows. In Encyclopedia of Earth. Edited by Cutler J. Cleveland; Environmental information coalition National Council for Science and the Environment, Washington, DC, USA, 2008.

Duarte, C. M., Losada, I. J., Hendriks, I. E., Mazarrasa, I. and Marbà, N.: The role of coastal plant communities for climate change mitigation and adaptation. Nature Climate Change, 3(11), 961-968. 
https://doi.org/10.1038/nclimate1970, 2013.

Duffy, J. P., Pratt, L., Anderson, K., Land, P. E. and Shutler, J. D.: Spatial assessment of intertidal seagrass meadows using optical imaging systems and a lightweight drone. Estuarine, Coastal and Shelf Science, 200, 169-180, 2018.

Dunton, K. H., and Schonberg, S. V.: Assessment of propeller scarring in seagrass beds of the south Texas coast: Journal Coastal Research, 37, 100-110, 2002.

ENVI: Continum $\quad$ Removal Tutorial. Boulder, Colorado, http://www.harrisgeospatial.com/docs/ContinuumRemoval.html , 2017.

Erftemeijer, P. L. A. and Shuail, D. A.: Seagrass Habitats in Arabian Gulf: Distribution, Tolerance Thresholds and Threats. Aquatic Ecosystem Health and Management, 15(1), 73-83, 2012.

Ferguson, R. L. and Wood, L. L.: Mapping Submerged Aquatic Vegetation in North Carolina with Conventional Aerial Photography. Federal Coastal Wetland Mapping Programs, National Ocean Pollution Policy Board's Habitat Loss and Modification Working Group. Biological Report, 90(18), pp. 125 - 132. Also available in web: https://apps.dtic.mil/sti/pdfs/ADA322827.pdf\#page=123, 1990.

Flood, N.: Comparing Sentinel-2A and Landsat 7 and 8 Using Surface Reflectance over Australia. Remote Sensing, 9, 659, 2017. DOI: 10.3390/rs9070659, 2017.

Fourqurean, J. W., Duarte, C. M., Kennedy, H., Marbà, N., Holmer, M., Mateo, M. A., Apostolaki, E. T., Kendrick, G. A., Krause-Jensen, D., McGlathery, K. D. and Serrano, O.: Seagrass ecosystems as a globally significant carbon stock. Nature Geoscience, 5(7), 505-509, 2012.

Fyfe, S. K.: Spatial and temporal variation in spectral reflectance: Are seagrass species spectrally distinct? Limnology and Oceanography, 48(1, part 2), 464-479. http://dx.doi.org/10.4319/lo.2003.48.1_part_2.0464, 2003.

Gascon, F., Bouzinac, C., Thépaut, O., Jung, M., Francesconi, B., Louis, J., Lonjou, V., Lafrance, B., Massera, S., Gaudel-Vacaresse, A., Languille, F., Alhammoud, B., Viallefont, F., Pflug, B., Bieniarz, J., Clerc, S., Pessiot, L., Trémas, T., Cadau, E., De Bonis, R., Isola, C., Martimort, P. and Fernandez, V.: Copernicus Sentinel-2A Calibration and Products Validation Status. Remote Sensing, 9, 584. https://doi.org/10.3390/rs9060584, 2017.

Gitelson, A. A., Kaufman, Y. J., Stark, R. and Rundquist, D.: Novel algorithms for remote estimation of vegetation fraction. Remote Sensing of Environment, 80, 76-87, 2002a.

Gitelson, A. A., Stark, R., Grits, U., Rundquist, D., Kaufman, Y. J. and Derry, D.: Vegetation and soil lines in visible spectral space: a concept and technique for remote estimation of vegetation fraction. Int. Journal of Remote Sensing, 23(13), 2537-2562, 2002b.

Green, E. P. and Short, F.: World atlas of seagrasses. Prepared by the UIMEP World Conservation Monitoring Centre. University of California Press, Berkeley, USA, Volume 47. Berkeley (California, USA): University of California. https://doi.org/10.1515/BOT.2004.029, 2003.

Grech, A., Chartrand-Miller, K., Erftemeijer, P., Fonseca, M., McKenzie, L., Rasheed, M. and Coles, R.: A comparison of threats, vulnerabilities and management approaches in global seagrass bioregions. Environmental Research Letters, 7(2), 024006, 2012. 
1000

1001

1002

1003

1004

1005

1006

1007

1008
Hamel, M. A. and Andréfouët, S.: Using very high resolution remote sensing for the management of coral reef fisheries: review and perspectives. Marine Pollution Bulletin, 60(9),1397-405. DOI: 10.1016/j.marpolbul.2010.07.002. Epub 2010 Jul 24, 2010.

Hashim, M., Misbari, S., Yahya, N. N., Ahmad, S., Reba, M. N. and Komatsu, T.: An approach for quantification of submerged seagrass biomass in shallow turbid coastal waters. In Proceedings of IGARSS, Quebec, Canada, pp. 4439-4442. DOI: 10.1109/IGARSS.2014.6947476, 2014.

Hedley, J., Roelfsema, C., Koetz, B. and Phinn, S.: Capability of the Sentinel 2 mission for tropical coral reef mapping and coral bleaching detection. Remote Sensing of Environment, 120, 145-155, 2012a.

Hedley, J. D., Roelfsema, C. M., Phinn, S. R. and Mumby, P. J.: Environmental and sensor limitations in optical remote sensing of coral reefs: implications for monitoring and sensor design. Remote Sensing, 4, 271-302. http://dx.doi.org/10.3390/rs4010271, 2012b.

Hossain, M. S., Bujang, J. S., Zakaria, M. H. and Hashim, M.: The application of remote sensing to seagrass ecosystems: An overview and future research prospects. Int. J. Remote Sensing, 36(1), 61-113, 2014.

Huang, Z., Turner, B. J., Dury, S. J., Wallis, I. R. and Foley, W. J.: Estimating foliage nitrogen concentration from HYMAP data using continuum removal analysis. Remote Sensing of Environment, 93, 18-29, 2004.

Huete, A. R.: A soil-adjusted vegetation index (SAVI). Remote Sensing of Environment, 25, 295-309, 1988.

Huete, A. R., Didan, K., Miura, T., Rodriguez, E. P., Gao, X. and Ferreira, L. G.: Overview of the radiometric and biophysical performance of the MODIS vegetation indices. Remote Sensing of Environment, 83(1), 195-213. http://dx.doi.org/10.1016/S0034-4257(02)00096-2, 2002.

Humood, N.: Human Impacts on Marine Biodiversity: Macrobenthos in Bahrain, Arabian Gulf. Chapter 7 (pp. 109126) in "The Importance of Biological Interactions in the Study of Biodiversity. Edited by J. LA $\tilde{A}^{3}$ pez-Pujol, ISBN: 978-953- 307-751-2. Published by InTech, 390 pp, 2011.

Hunt, Jr. E. R., Doraiswamy, P. C., McMurtrey, J. E., Daughtry, C. S. T., Perry, E. M., and Akhmedov, B.: A visible band index for remote sensing leaf chlorophyll content at the canopy scale. Int. Journal of Applied Earth Observation and Geoinformation, 21, 103-112, 2013.

Indayani, A. B., Danoedoro, P., Wicaksono, P., Winarso, G. and Setiawan, K. T.: Spectral Analysis from Absorption and Reflectance of Seagrass Leaves using Trios-Ramses Spectroradiometer in Nusa Lembongan and Pemuteran, Bali. Jurnal Penginderaan Jauh dan Pengolahan Data Citra Digital, 17(2), 103-113. http://dx.doi.org/10.30536/j.pjpdcd.2020.v17.a3384, 2020.

Irons, J. R. Dwyer, J. L. and Barsi, J. A.: The next Landsat satellite: the Landsat data continuity mission. Remote Sensing of Environment, 122, 11-21. https://doi.org/10.1016/j.rse.2011.08.026, 2012.

Jackson, R. D, Pinter, P. J., Paul, J., Reginato, R. J., Robert, J. and Idso, S. B.: Hand-Held Radiometry. Agricultural Reviews and Manuals, ARM-W-19; U.S. Department of Agriculture Science and Education Administration: Phoenix, AZ, USA, 1980.

James, M. E. and Kalluri, S. N. V.: The Pathfinder AVHRR land data set: an improved coarse resolution data set for terrestrial monitoring. Int. Journal of Remote Sensing, 15(17), 3347-3363, 1994. 
Johnsen, G. and Sakshaug, E.: Biooptical characteristics of PSII and PSI in 33 species (13 pigment groups) of marine phytoplankton, and the relevance for pulse amplitude-modulated and fast-repetition-rate fluorometry1. Journal of Phycology, 43, 1236-1251, 2007.

Joyce, K. E., Phinn, S. R. and Roelfsema, C. M.: Live coral cover index testing and application with hyperspectral airborne image data. Remote Sensing, 5(11), 6116-6137. http://dx.doi.org/10.3390/rs5116116, 2013.

Kibele, J.: Submerged habitats from space: Increasing map production capacity with new methods and software. PhD Thesis, Institute of Marine Science, the University of Auckland, New-Zeeland, 179 pp, 2017.

Kirk, J. T. O.: Light and photosynthesis in aquatic ecosystems, $2^{\text {nd }}$ edition. Cambridge university press, 509 pp. https://doi.org/10.1017/CBO9780511623370, 1994.

Knight, E. and Kvaran, G.: Landsat-8 operational land imager design, characterization and performance. Remote Sensing, 6(11), 10286-10305, 2014.

Knudby, A. and Nordlund, L.: Remote sensing of seagrasses in a patchy multi-species environment. Int. Journal of Remote Sensing, 32(8), 2227-2244, 2011.

Kokaly, R. F., Despain, D. G., Clark, R. N. and Livo, K. E.: Mapping vegetation in Yellowstone National Park using spectral feature analysis of AVIRIS data. Remote Sensing of Environment, 84, 437-456, 2003.

Komatsu, T., Hashim, M., Nurdin, N., Noiraksar, T., Prathep, A., Stankovic, M., Hoang-Son, T. P., Thu, P. M., Luong, C. V., Wouthyzen, S., Phauk, S., Muslim, A. M., Yahya, N. N., Terauchi, G., Sagawa, T. and Ken-ichi Hayashizaki, K.-H.: Practical mapping methods of seagrass beds by satellite remote sensing and ground trothing. Coastal Marine Science, 43(1), 1-25, 2020.

Konstantinos, T., Spyridon, C. S., Apostolos, P. and Nikolaos, S.: The use of Sentinel-2 imagery for seagrass mapping: Kalloni Gulf (Lesvos Island, Greece) case study. Proceedings of the SPIE, Volume 9688, Fourth International Conference on Remote Sensing and Geoinformation of the Environment (RSCy2016), 96881F. Doi:10.1117/12.2242887, http://dx.doi.org/10.1117/12.2242887, 2016.

Kovacs, E., Roelfsema, C., Lyons, M., Zhao, S. and Phinn, S.: Seagrass habitat mapping: how do Landsat 8 OLI, Sentinel-2, ZY-3A, and Worldview-3 perform? Remote Sensing Letters, 9(7), 686-695, 2018.

Larkum, A. W. D., Orth, R. J. and Duarte, C. M.: Seagrasses: Biology, ecology and conservation. Seagrasses: Biology, Ecology and Conservation. https://doi.org/10.1007/978-1-4020-2983-7, 2006.

Leleu, K., Alban, F., Pelletier, D., Charbonnel, E., Letourneur, Y. and Boudouresque, C.F.: Fishers' perceptions as indicators of the performance of Marine Protected Areas (MPAs). Marine Policy, 36(2), 414-422. https://doi.org/10.1016/j.marpol.2011.06.002, 2012.

Li, J. and Chen, B.: Global Revisit Interval Analysis of Landsat-8 -9 and Sentinel-2A-2B Data for Terrestrial Monitoring. Sensors, 20, 6631. https://doi.org/10.3390/s20226631, 2020.

Li, J. and Roy, D. P.: A Global Analysis of Sentinel-2A, Sentinel-2B and Landsat-8 Data Revisit Intervals and Implications for Terrestrial Monitoring. Remote Sensing, 9, 902. DOI: 10.3390/rs9090902, 2017.

Li, S., Ganguly, S., Dungan, J. L., Wang, W. L. and Nemani, R. R.: Sentinel-2 MSI Radiometric Characterization and Cross-Calibration with Landsat-8 OLI. Advances in Remote Sensing, 6, 147-159. DOI : 10.4236/ars.2017.62011., 2017. 
Li, R., Liu, J.-K., Sukcharoenpong, A., Yuan, J., Zhu, H. and Zhang, S.: A Systematic Approach toward Detection of Seagrass Patches from Hyperspectral Imagery, Marine Geodesy, 35(3), 271-286, 2012.

Li, S.: Seagrass Mapping and Human Impact Evaluation Using Remote Sensing Imagery at Core Banks, North Carolina. Duke University, 2018.

Lin, C., Gong, Z. and Zhao, W.: The extraction of wetland hydrophytes types based on medium resolution TM data. Shengtai Xuebao/Acta Ecologica Sinica, 30(23), 6460-6469, 2010.

Loveland, T. R. and Dwyer, J. L.: Landsat: Building a strong future. Remote Sensing of Environment, 122, $22-29$. https://doi.org/10.1016/j.rse.2011.09.022, 2012.

Lyimo, L. D.: Carbon sequestration processes in tropical seagrass beds. PhD Thesis, Department of Ecology, Environment and Plant Sciences, Stockholm University, Sweden, 2016.

Lyons M. B., Phinn S. R. and Roelfsema C. M.: Integrating Quickbird Multi-Spectral Satellite and Field Data: Mapping Bathymetry, Seagrass Cover, Seagrass Species and Change in Moreton Bay, Australia in 2004 and 2007. Remote Sensing, 3, 42-64. doi:http://dx.doi.org/10.3390/rs3010042., 2011.

Lyons, M. B ., Phinn, S. R. and Roelfsema, C. M.: Long term land cover and seagrass mapping using Landsat and object-based image analysis from 1972 to 2010 in the coastal environment of South East Queensland, Australia. ISPRS Journal of Photogrammetry and Remote Sensing, 71, 34-46, 2012.

Lyons, M. B., Roelfsema, C. M., and Phinn, S. R.: Towards understanding temporal and spatial dynamics of seagrass landscapes using time-series remote sensing. Estuarine, Coastal and Shelf Science, 20, 42-53, 2013.

Luczkovich, J., Wagner, T., Michalek, J. and Stoffle, R.: Discrimination of coral reefs, seagrass meadows, and sand bottom types from space: a Dominican Republic case study. Photogrammetric Engineering and Remote Sensing, 59(3), 385-389, 1993.

Mandanici, E. and Bitelli, G.: Preliminary Comparison of Sentinel-2 and Landsat 8 Imagery for a Combined Use. Remote Sensing, 8, 1014, 2016. DOI:10.3390/rs8121014., 2016.

Manevski, K., Manakos, I., Petropoulos, G. P. and Kalaitzidis, C.: Discrimination of common Mediterranean plant species using field Spectroradiometry. Int. J. of Applied Earth Observation and Geoinformation, 13, 922-933, 2011.

Marcello, J., Eugenio, F., Martín, J. and Marqués, F.: Seabed Mapping in Coastal Shallow Waters Using High Resolution Multispectral and Hyperspectral Imagery. Remote Sensing, 10, 1208. DOI:10.3390/rs10081208, 2018.

Markham, B., Barsi, J., Kvaran, G., Ong, L., Kaita, E., Biggar, S., Czapla-Myers, J., Mishra, N. and Helder, D.: Landsat-8 Operational Land Imager Radiometric Calibration and Stability. Remote Sensing, 6(12), 12275-12308. https://doi.org/10.3390/rs61212275, 2014.

Markham, B., Jenstrom, D., Masek, J. G., Dabney, P., Pedelty, J. A., Barsi, J.A. and Montanaro, M.: Landsat 9: Status and plans. In Earth Observing Systems XXI; International Society for Optics and Photonics: San Diego, CA, USA; Volume 9972, p. 99720G, 2016.

Mcfeeters, S. K.: The use of the normalized difference water index (NDWI) in the delineation of open water features. Int. Journal of Remote Sensing, 17, 1425-1432, 1996. 
Meehan, A. J., Williams, R. J. and Watford, F. A.: Detecting Trends in Seagrass Abundance Using Aerial Photograph Interpretation: Problems Arising with the Evolution of Mapping Methods. Estuaries, 28(3), 462-472, 2005.

Mount, R. E.: Rapid monitoring of extent and condition of seagrass habitats with aerial photography "mega-quadrats. Journal of Spatial Science, 52 (1), 105-119, 2007.

Morrison, M. A., Lowe, M. L., Grant, C. M., Smith, P. J., Carbines, G., Reed, J., Bury, S. J. and Brown, J. (2014) Seagrass meadows as biodiversity and productivity hotspots. New Zealand Aquatic Environment and Biodiversity, Report No. 137, 151 pages. http://www.mpi.govt.nz/news-resources/publications.aspx, 2014.

Mumby, P. J., Green, E. P., Edwards, A. J. and Clark, C. D.: Measurement of Seagrass Standing Crop using Satellite and Digital Airborne Remote Sensing. Marine Ecology Progress Series, 159, 51-60, 1997.

NASA (2014) Landsat-8 Instruments. Available online (accessed on 18 March 2021): http://www.nasa.gov/mission_pages/landsat/spacecraft/index.html, 2014.

NASA: Landsat-9 Mission Details. Available online (accessed on 18 March 2021). https://landsat.gsfc.nasa.gov/landsat-9/landsat-9-mission-details/, 2019.

NASA: Landsat-9 overview, continuity the legacy - 2021 and beyond. https://landsat.gsfc.nasa.gov/landsat-9/landsat9-overview, 2021

Neckles, H. A., Kopp, B. S., Peterson, B. J. and Pooler, P. S.: Integrating Scales of Seagrass Monitoring to Meet Conservation Needs. Estuaries and Coasts, 35(1), 23-46, 2012.

Novak, A. B and Short, F. T.: Submerged Aquatic Vegetation: Seagrasses. Encyclopedia of Natural Resources, 9 pages. DOI: 10.1081/E-ENRW-120047540, 2014.

Onuf, C. P.: Seagrasses, dredging and light in Laguna Madre, Texas, U.S.A.: Estuarine, Coastal and Shelf Science, 39, 75-91, 1994.

Orth, R. J., Carruthers, T. J. B., Dennison, W. C., Duarte, C. M., Fourqurean, J. W., Heck, K. L., Hughes, A. R., Kendrick, G. A., Kenworthy, W. J., Olyarnik, S. Short, F. T., Waycott, M. and Williams, S. L.: A Global Crisis for Seagrass Ecosystems. Bioscience, 56(12), 987-996. https://doi.org/10.1641/00063568(2006)56[987:AGCFSE]2.0.CO;2, 2006.

Pasqualini, V., Pergent-Martini, C., Pergent, G., Agreil, M., Skoufas, G., Sourbes, L. and Tsirika, A.: Use of SPOT 5 for mapping seagrasses: An application to Posidonia oceanica. Remote Sensing of Environment, 94(1), 39-45, 2005.

Pastick, N. J., Wylie, B. K. and Wu, Z.: Spatiotemporal Analysis of Landsat-8 and Sentinel-2 Data to Support Monitoring of Dryland Ecosystems. Remote Sensing, 10, 791. DOI: 10.3390/rs10050791, 2018.

Peneva, E., Griffith, J. A. and Carter, G. A.: Seagrass mapping in the northern Gulf of Mexico using airborne hyperspectral imagery: a comparison of classification methods. Journal of Coastal Research, 24(4), 850-856, 2008. Perez, D., Islam, K., Hill, V., Zimmerman, R., Schaeffer, B., Shen, Y. and Li, J.: Quantifying Seagrass Distribution in Coastal Water with Deep Learning Models. Remote Sensing, 12, 1581. DOI:10.3390/rs12101581, 2020.

Peterson, B. J. and Fourqurean, J. W.: Large-scale patterns in seagrass (Thalassia testudinum) demographics in south Florida. Limnology and Oceanography, 46(5), 1077-1090, 2001. 
Phinn, S., Roelfsema, C., Dekker, A., Brando, V. and Anstee, J.: Mapping seagrass species, cover and biomass in shallow waters: An assessment of satellite multispectral and airborne hyper-spectral imaging systems in Moreton Bay (Australia). Remote Sensing of Environment, 112(8), 3413-3425, 2008.

Preen, A.: Distribution, abundance and conservation status of dugongs and dolphins in the southern and western Arabian Gulf. Biological Conservation, 118(2), 205-218, 2004.

Pu, R., Bell, S., Baggett, L., Meyer, C. and Zhao, Y.: Discrimination of Seagrass Species and Cover Classes with in situ Hyperspectral Data. Journal of Coastal Research, 28(6),1330-1344, 2012.

Ressom, H., Fyfe, S. K., Natarajan, P. and Snrangam, S.: Monitoring Seagrass Health Using Neural Networks. Proceedings of IGARSS 2003, pp. 1019-1024, 2003.

Richardson, A. J. and Wiegand, C. L.: Distinguishing vegetation from soil background information. Photogrammetric Engineering and Remote Sensing, 43(12), 1541-1552, 1977.

Roelfsema, C. M., Lyons, M., Kovacs, E. M., Maxwell, P., Saunders, M. I., Samper-Villarreal, J. and Phinn, S. R.: Multi-temporal mapping of seagrass cover, species and biomass: A semi-automated object based image analysis approach. Remote Sensing of Environment, 150, 172-187, 2014.

Roelfsema, C. M., Phinn, S. R., Udy, N. and Maxwell, P.: An integrated field and remote sensing approach for mapping seagrass cover, Moreton Bay, Australia. Journal of Spatial Science, 54(1), 45-62. https://doi.org/10.1080/14498596.2009.9635166, 2009.

Rouse, J. W., Haas, R. W., Schell, J. A., Deering, D. W., Harlan, J. C. (1974) Monitoring the vernal advancement and retrogradation (Greenwave effect) of natural vegetation. NASA/GSFC Type-III Final Report, Greenbelt, Maryland, U.S.A., 164 pp, 1974.

Roy, D. P., Li, J., Zhang, H. K., Yan, L., Huang, H. and Li, Z.: Examination of Sentinel-2A multi-spectral instrument (MSI) reflectance anisotropy and the suitability of a general method to normalize MSI reflectance to nadir BRDF adjusted reflectance. Remote Sensing of Environment, 199, 25-38. https://doi.org/10.1016/j.rse.2017.06.019, 2017.

Roy, D., Zhang, H., Ju, J., Gomez-Dans, J., Lewis, P., Schaaf, C., Sun, Q., Li, J., Huang, H. and Kovalskyy, V.: A general method to normalize Landsat reflectance data to nadir BRDF adjusted reflectance. Remote Sensing of Environment, 176, 255-271. https://doi.org/10.1016/j.rse.2016.01.023, 2016.

Roy, D. P., Wulder, M. A., Loveland, T. R., Woodcock, C. E., Allen, R. G., Anderson, M. C., Helder, D., Irons, J. R., Johnson, D. M., Kennedy, R., Scambos, T. A., Schaaf, C. B., Schott, J. R., Sheng, Y., Vermote, E. F., Belward, A. S., Bindschadler, R., Cohen, W. B., Gao, F., Hipple, J. D., Hostert, P., Huntington, J., Justice, C. O., Kilic, A., Kovalskyy, V., Lee, Z. P., Lymburner, L., Masek, J. G., McCorkel, J., Shuai, Y., Trezza, R., Vogelmann, J., Wynne,R. H. and Zhu, Z.: Landsat-8: science and product vision for terrestrial global change research. Remote Sensing of Environment, 145, 154-172. https://doi.org/10.1016/j.rse.2014.02.001, 2014.

Saarman, E., Gleason, M., Ugoretz, J., Airamé, S., Carr, M., Fox, E., Frimodig, A., Mason, T. and Vasques, J.: The role of science in supporting marine protected area network planning and design in California, Ocean and Coastal Management, 74, 45-56. https://doi.org/10.1016/j.ocecoaman.2012.08.021, 2013. 
Sandmeier, St., Muller, Ch., Hosgood, B. and Andreoli, G.: Sensitivity Analysis and quality Assessment of Laboratory BRDF Data. Remote Sensing of Environment, 64, 176-191, 1998.

Shapiro, A. C. and Rohmann, S. O.: Mapping changes in submerged aquatic vegetation using Landsat imagery and benthic habitat data: Coral reef ecosystem monitoring in Vieques Sound between 1985 and 2000. Bulletin of Marine Science, 79(2), 375-388, 2006.

Short, F. T. and Wyllie-Echeverria, S.: Natural and humaninduced disturbance of seagrasses. Environ. Conserv., 23, 17-27, 1996.

Short, F. T. and Coles, R.: Global Seagrass Research Methods. Elsevier Publishing, The Netherlands, 482 pp, 2001.

Short, F. T., Polidoro, B., Livingstone, S. R., Carpenter, K. E., Bandeira, S., Bujang, J. S., Calumpong, H. P., Carruthers, T. J. B., Coles, R. G., Dennison, W. C., Erftemeijer, P. L. A., Fortes, M. D., Freeman, A. S., Jagtap, T. G., Kamal-Abu-Hena, M., Kendrick, G. A., Kenworthy, W. J., La-Nafie, Y. A., Nasution, I. M., Orth, R. J., Prathep, A., Sanciangco, J. C., Tussenbroek, B. V., Vergara, S. G., Waycott, M. W. and Zieman, J. C.: Extinction risk assessment of the world's seagrass species. Biological Conservation, 144(7), 1961-1971. https://doi.org/10.1016/j.biocon.2011.04.010, 2011.

Silva, T. S. F., Costa, M. P. F., Melack, J. M., and Novo, E. M. L. M.: Remote sensing of aquatic vegetation: Theory and applications. Environmental Monitoring and Assessment, 140(1-3), 131-145. https://doi.org/10.1007/s10661007-9855-3, 2008.

Skakun, S., Roger, J.-C., Vermote, E. F., Masek, J. G. and Justice, C. O.: Automatic sub-pixel co-registration of Landsat-8 Operational Land Imager and Sentinel-2A Multi-Spectral Instrument images using phase correlation and machine learning based mapping. Int. J. of Digital Earth, 10(12), 1253-1269. http://dx.doi.org/10.1080/17538947.2017.1304586, 2017.

Slater, P. N.: Remote Sensing - Optics and Optical System. Addison-Wesley, reading, MA, 575 pp. 1980.

Teillet, P. M. and Santer, R.: Terrain Elevation and Sensor Altitude Dependence in a Semi-Analytical Atmospheric Code". Canadian J. of Remote Sensing, 17, 36-44, 1991.

Thakur, Y. et al.: Sea Turtles. Chapter 9, pp. 165-177. In Marine Environment and Resources of Abu Dhabi, edited by T.Z. Al-Abdessalam, published by Environment Agency of Abu-Dhabi, UAE, 255 pp, 2007.

Thorhaug, A., Richardson, A. D. and Berlyn, G. P.: Spectral reflectance of the seagrasses: Thalassia testudinum, Halodule wrightii, Syringodium filiforme and five marine algae. Int. Journal of Remote Sensing, 28(7), $1487-$ 1501, 2007.

Traganos, D.: Development of seagrass monitoring techniques using remote sensing data. PhD Thesis, Osnabrück University, Osnabrück in Lower Saxony, Germany, 199 pp, 2020.

Uhrin, A. V. and Townsend, P. H.: Improved Seagrass Mapping Using Linear Spectral Unmixing of Aerial Photographs. Estuarine, Coastal and Shelf Science, 171, 11-22, 2016.

Umamaheswari, R., Ramachandran, S. and Nobi, E. P.: Mapping the extend of seagrass meadows of Gulf of Mannar Biosphere Reserve, India using IRS ID satellite imagery. Int. Journal of Biodiversity and Conservation, 1(5), 187193, 2009. 
Van-Der-Meera, F.: Analysis of spectral absorption features in hyperspectral imagery. Int. J. Appl. Earth Observation and Geoinformation, 5, 55-68, 2004.

Van der Werff, H. and Van der Meer, F.: Sentinel-2A MSI and Landsat 8 OLI Provide Data Continuity for Geological Remote Sensing. Remote Sensing, 8, 883. https://doi.org/10.3390/rs8110883, 2016.

Vermote, E., Justice, C., Claverie, M. and Franch, B.: Preliminary analysis of the performance of the Landsat 8/OLI land surface reflectance product. Remote Sensing of Environment, 185(2), 46-56. DOI: 10.1016/j.rse.2016.04.008, 2016 .

Villa, P., Bresciani, M., Braga, F. and Bolpagni, R.: Comparative Assessment of Broadband Vegetation Indices over Aquatic Vegetation. IEEE Journal of Selected Topics in Applied Earth Observations and Remote Sensing, 7(7), 3117-3127, 2014.

Villa, P., Mariano Bresciani, M., Braga, F. and Bolpagni, R.: Mapping Aquatic Vegetation through Remote Sensing Data: A Comparison of Vegetation Indices Performances. 6th EARSeL Workshop on Remote S. of the Coastal Zone, 7-8 June 2013, Matera, Italy, pp. 10-15, 2013.

Vuolo, F., Zółtak, M., Pipitone, C., Zappa, L., Wenng, H., Immitzer, M., Weiss, M., Baret, F. and Atzberger, C.: Data service platform for Sentinel-2 surface reflectance and value-added products: System use and examples. Remote Sensing, 8, 938, 2016.

Wabnitz, C. C., Andréfouët, S., Torres-Pulliza, D., Muller-Karger, F. E. and Kramer, P. A.: Regional-scale seagrass habitat mapping in the Wider Caribbean region using Landsat sensors: Applications to conservation and ecology. Remote Sensing of Environment, 12(8), 3455-3467, 2008.

Warren, C., Dupont, J., Abdel-Moati, M., Hobeichi, S., Palandro, D. and Purkis, S.: Remote sensing of Qatar nearshore habitats with perspectives for coastal management. Marine Pollution Bulletin, 105(2), 641-653. https://doi.org/10.1016/j.marpolbul.2015.11.036, 2016.

Waycott, M., Duarte, C. M., Carruthers, T. J. B., Orth, R. J., Dennison, W. C., Olyarnik, S., Calladine, A., Fourqurean, J. W., Heck Jr., K. L., Hughes, A. R., Kendrick, G. A., Kenworthy, W. J., Short, F. T. and Williams, S. L.: Accelerating loss of seagrasses across the globe threatens coastal ecosystems. PNAS July 28, 2009; 106 (30) 12377-12381; www.pnas.org/cgi/doi/10.1073/pnas.0905620106, 2009.

Wicaksono, P. and Hafizt, M.: Mapping Seagrass from Space: Addressing the Complexity of Seagrass LAI Mapping, European Journal of Remote Sensing, 46(1), 18-39. http://dx.doi.org/10.5721/EuJRS20134602, 2013.

Wicaksono, P., Fauzan, M. A., Kumara, I. S. W., Yogyantoro, R. N., Lazuardi, W. and Zhafarina, Z.: Analysis of reflectance spectra of tropical seagrass species and their value for mapping using multispectral satellite images. Int. Journal of Remote Sensing, 40(23), 8955-8977. DOI: 10.1080/01431161.2019.1624866, 2019.

Wicaksono, P., Kumara, I. S., Kamal, M., Fauzan, A. M., Zhafarina, Z., Nurswantoro, D. A. and Yogyantoro, R. N.: Multispectral Resampling of Seagrass Species Spectra: WorldView-2, Quickbird, Sentinel-2A, ASTER VNIR, and Landsat 8 OLI. The $5^{\text {th }}$ Geoinformation Science Symposium 2017 (GSS 2017). IOP Conf. Series: Earth and Environmental Science, 98(2017), 012039. DOI:10.1088/1755-1315/98/1/012039, 2017.

Willmott, C.J.: Some comments on the evaluation of model performance. Bull. Am. Meteorol. Soc., 63, 1309-1313, 1982. 
Wood, J. S.: Hyperspectral analysis of seagrass in Redfish Bay, Texas. Ph.D. Thesis, Texas A\&M University-Corpus Christi, Corpus Christi, Texas (USA), 141 pp, 2012.

Wulder, M. A., Hilker, T., White, J. C., Coops, N. C., Masek, J. G., Pflugmacher, D. and Crevier, Y.: Virtual constellations for global terrestrial monitoring. Remote Sensing of Environment, 170, 62-76. https://doi.org/10.1016/j.rse.2015.09.001, 2015.

Yan, L., Roy, D.P., Li, Z., Zhang, H.K. and Huang, H.: Sentinel-2A multi-temporal misregistration characterization and an orbit-based sub-pixel registration methodology. Remote Sensing of Environment, 215, 495-506. https://doi.org/10.1016/j.rse.2018.04.021, 2018.

Yang, D. and Yang, C.: Seagrass Distribution in China with Satellite Remote Sensing. Chapter 4 in Remote Sensing of Planet Earth, edited by Yann Chemin, pp. 75-94. ISBN: 978-953-307-919-6, InTech. Available from: http://www.intechopen.com/books/remote-sensing-of-planet-earth/seagrass-distribution-in-china-withremotesensing, 2012.

Yang, D. and Yang, C.: Detection of seagrass distribution changes from 1991 to 2006 in Xincun Bay, Hainan, with satellite remote sensing. Sensors, 9(2), 830-844, 2009.

Zhang, H. K. and Roy, D. P.: Computationally inexpensive Landsat-8 operational land imager (OLI) pan-sharpening. Remote Sensing, 8 (3), 180, 2016.

Zhang, H. K., Roy, D. P., Yan, L., Li, Z., Huang, H., Vermote, E., Skakun, S. and Roger, J. C.: Characterization of Sentinel-2A and Landsat-8 top of atmosphere, surface, and nadir BRDF adjusted reflectance and NDVI differences. Remote Sensing of Environment, 215, 482-494. https://doi.org/10.1016/j.rse.2018.04.031, 2018.

Zhao, D., Lv, M., Jiang, H., Cai, Y., Xu, D. and An, S.: Spatio-Temporal Variability of Aquatic Vegetation in Taihu Lake over the Past 30 Years. PLoS ONE, 8(6), 6-12. https://doi.org/10.1371/journal.pone.0066365, 2013.

Zoffoli, M. L., Gernez, P., Rosa, P., Le-Bris, A., Brando, V. E., Barille, A.-L., Harin, N., Peters, S., Poser, K., Spaias, L., Peralta, G. and Barille, L.: Sentinel-2 remote sensing of Zostera noltei-dominated intertidal seagrass meadows. Remote Sensing of Environment, 251, 112020, 2020.

Zorrilla, N. A., Vantrepotte, V., Ngoc, D.-D., Huybrechts, N. and Gardel, A.: Automated SWIR based empirical sun glint correction of Landsat 8-OLI data over coastal turbid water. Optics Express, 27(8), A294-A318. https://doi.org/10.1364/OE.27.00A294, 2019. 
https://doi.org/10.5194/os-2021-81

Preprint. Discussion started: 25 November 2021

(c) Author(s) 2021. CC BY 4.0 License.

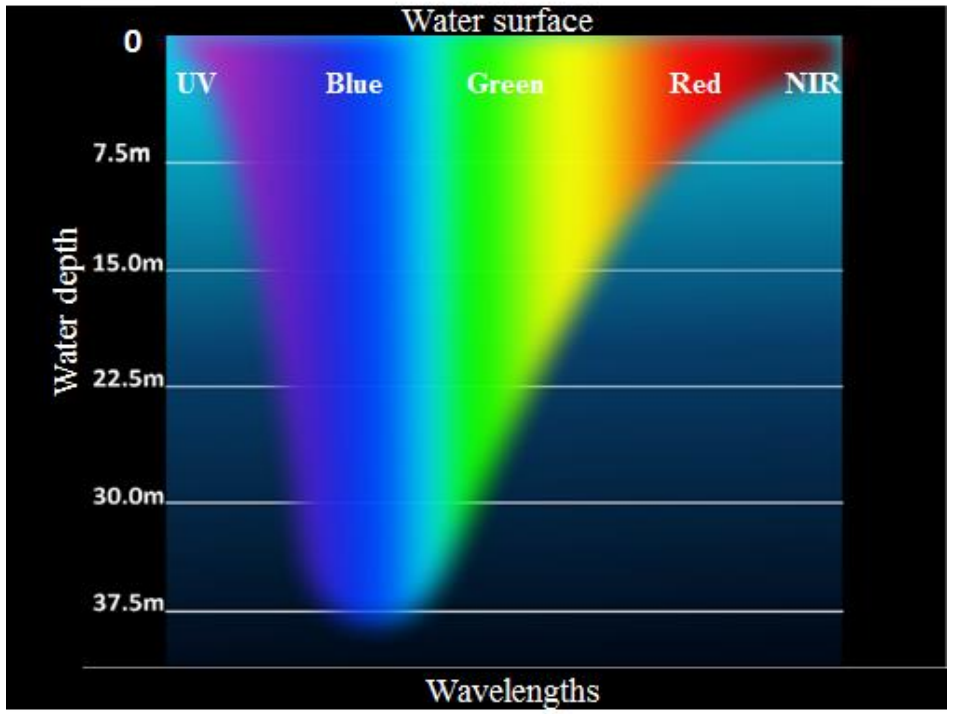

1260 Figure 1. Vertical penetration of electromagnetic spectrum in shallow water (adapted from: Morris, 2019),

1261 https://commons.wikimedia.org/wiki/Category:Visible_spectrum_illustrations)

1264

1265

1266

1267

1268 
https://doi.org/10.5194/os-2021-81

Preprint. Discussion started: 25 November 2021

(c) Author(s) 2021. CC BY 4.0 License.

Ocean Science

Discussions

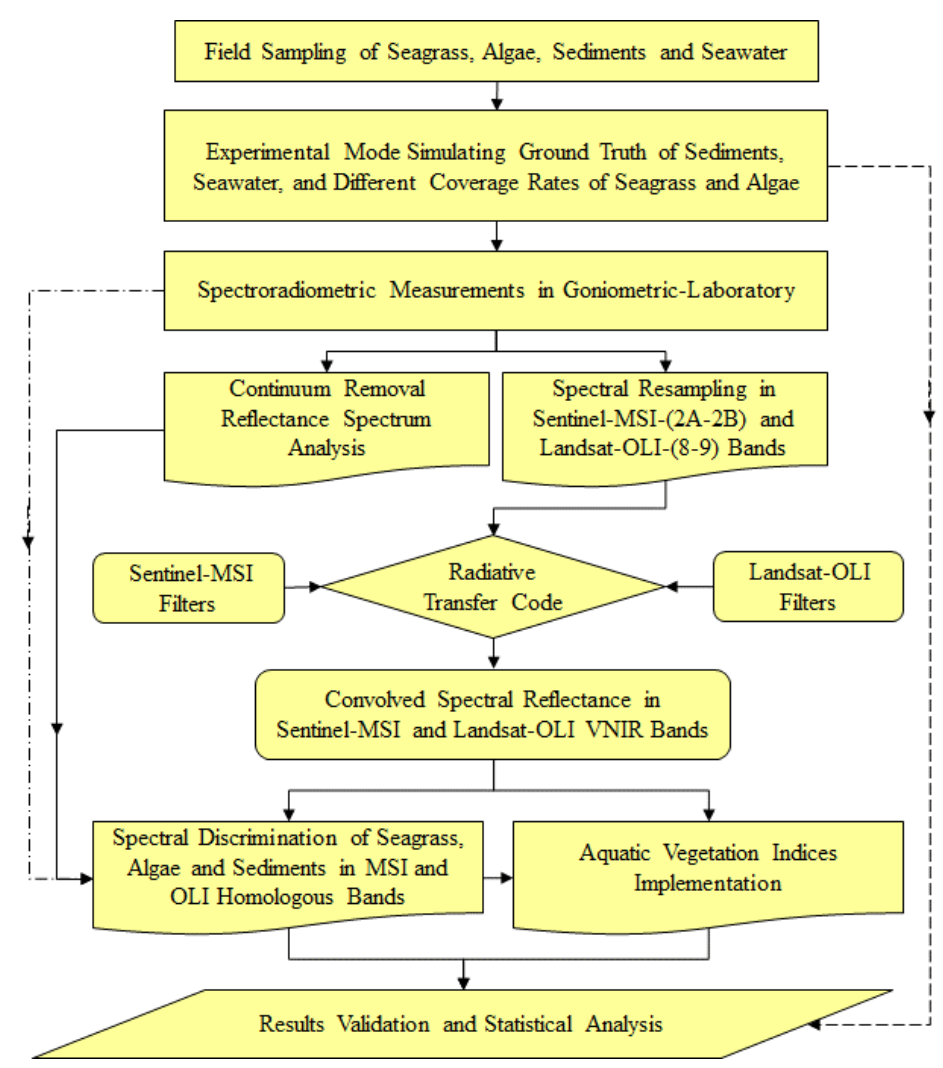

Figure 2. Methodology Flowchart

1271

1272 


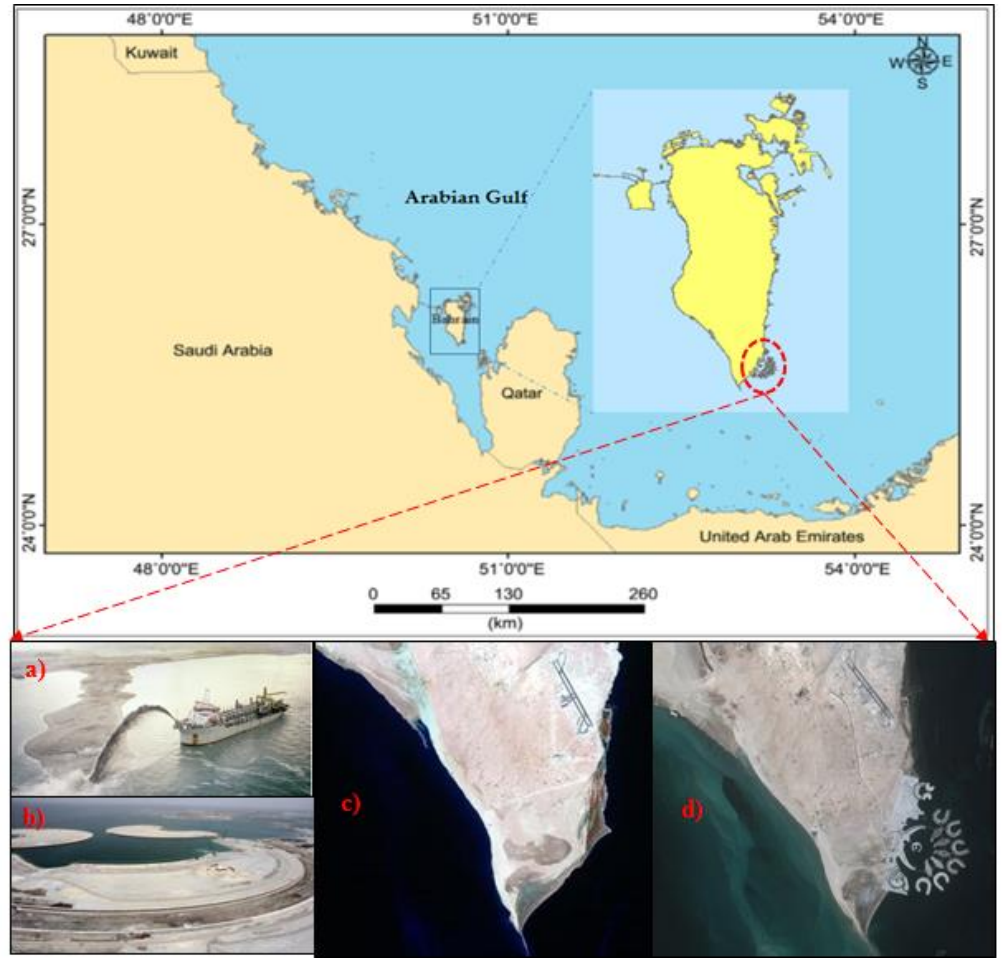

Figure 3. Study site (Kingdom of Bahrain), photos illustrating dredging operations (a and b), and satellite images of the south part of Bahrain before (c) and after (d) artificial islands construction.

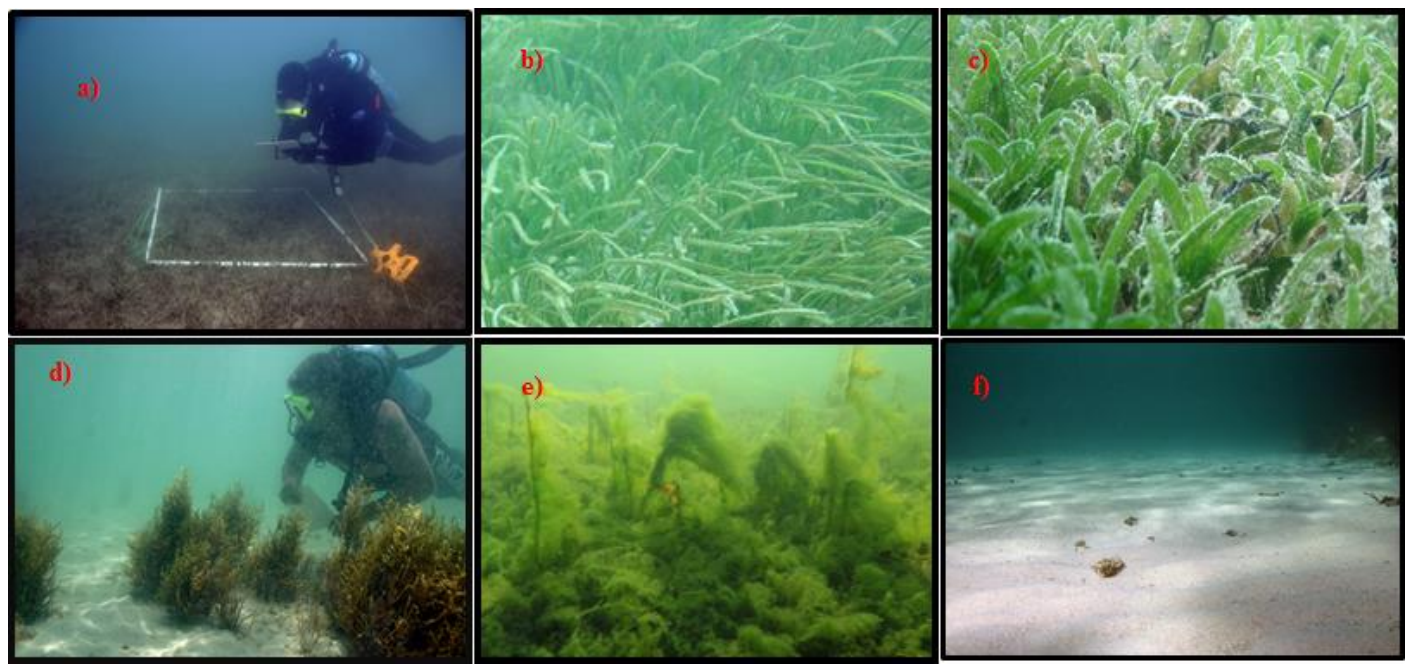

Figure 4. Diver for sampling operation (a), and underwater photos of the considered seagrass and algae species: HU (b), HS (c), BA (d), GA (e), and bright sediments (f). 
https://doi.org/10.5194/os-2021-81

Preprint. Discussion started: 25 November 2021

(c) Author(s) 2021. CC BY 4.0 License.
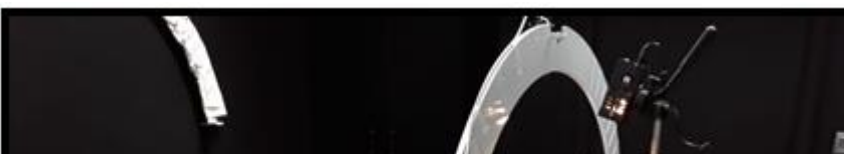

Figure 5: Dark Goniometric-Laboratory for ASD measurements.

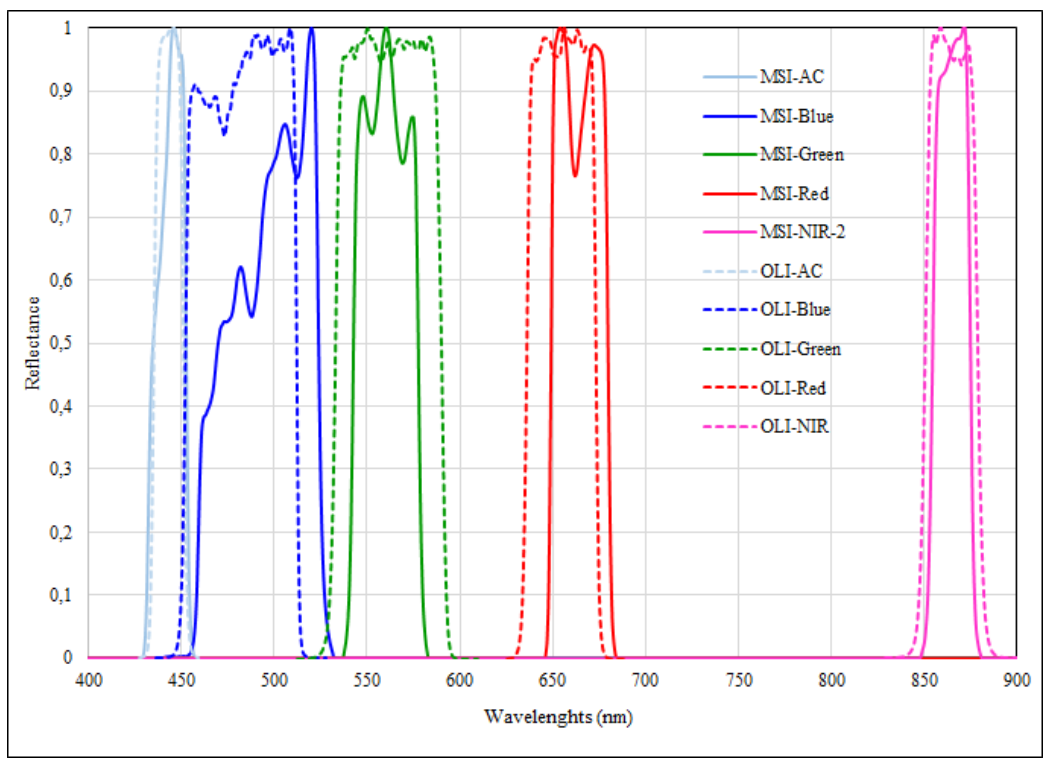

Figure 6. Sentinel-MSI and Landsat-OLI relative spectral response profiles characterizing the filters of each spectral band in the VNIR. 
https://doi.org/10.5194/os-2021-81

Preprint. Discussion started: 25 November 2021

(c) Author(s) 2021. CC BY 4.0 License.
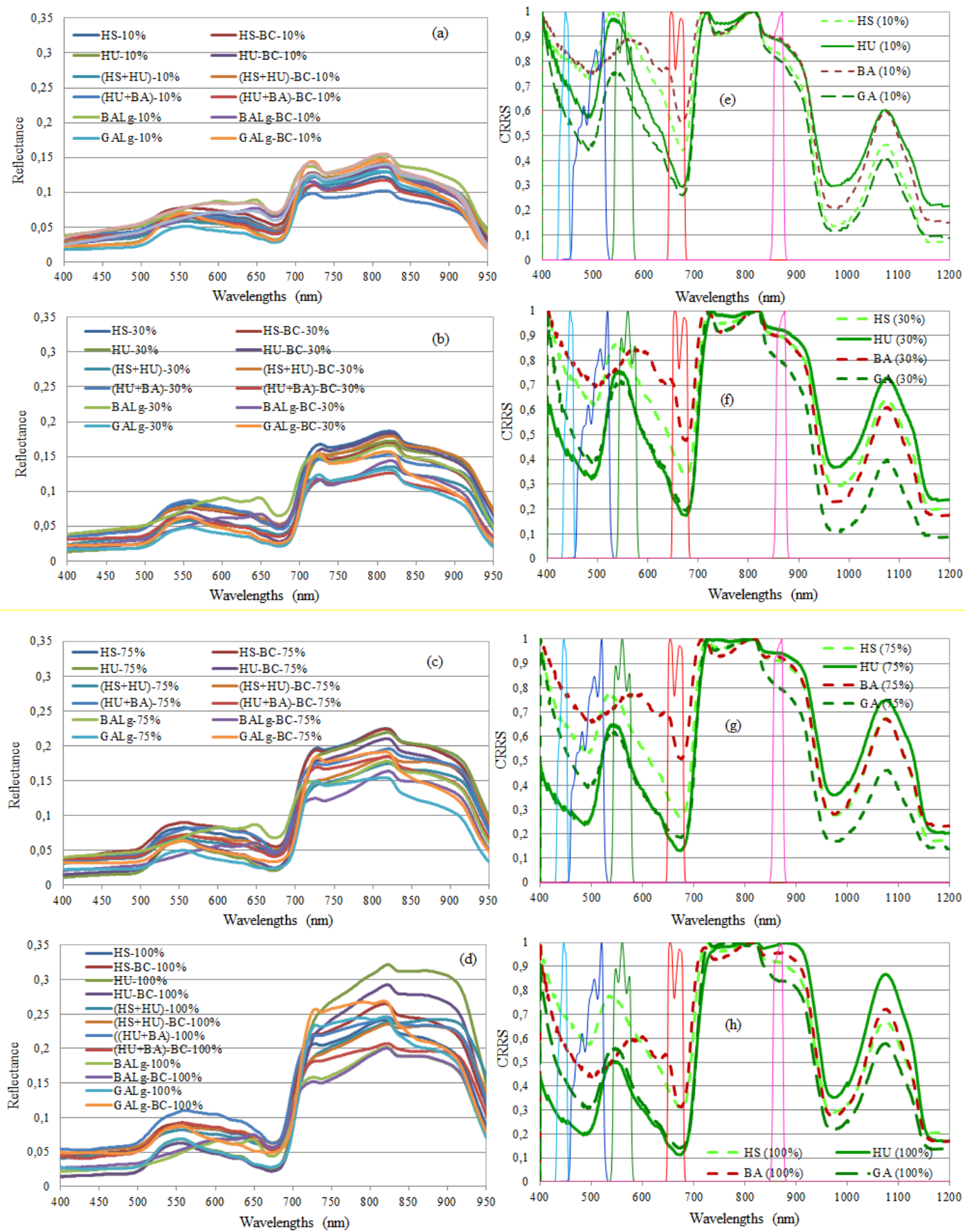

Figure 7. Spectral signatures of seagrass and algae samples at different coverage rates and CRRS transformations. 
https://doi.org/10.5194/os-2021-81

Preprint. Discussion started: 25 November 2021

(c) Author(s) 2021. CC BY 4.0 License.
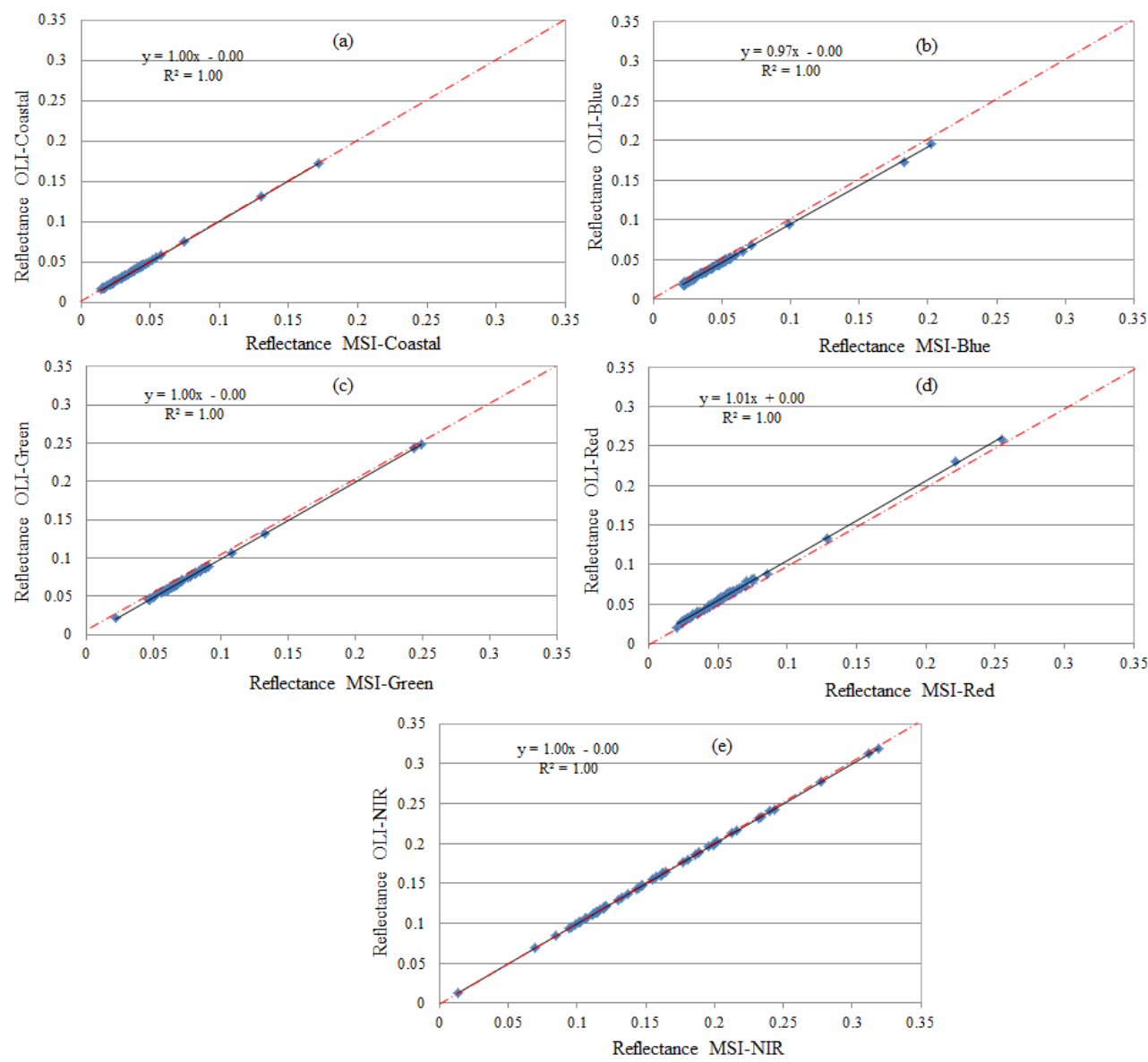

Figure 8. Scatter-plots of reflectances sampled and convolved in MSI and OLI homologous spectral bands. 
https://doi.org/10.5194/os-2021-81

Preprint. Discussion started: 25 November 2021

(c) Author(s) 2021. CC BY 4.0 License.
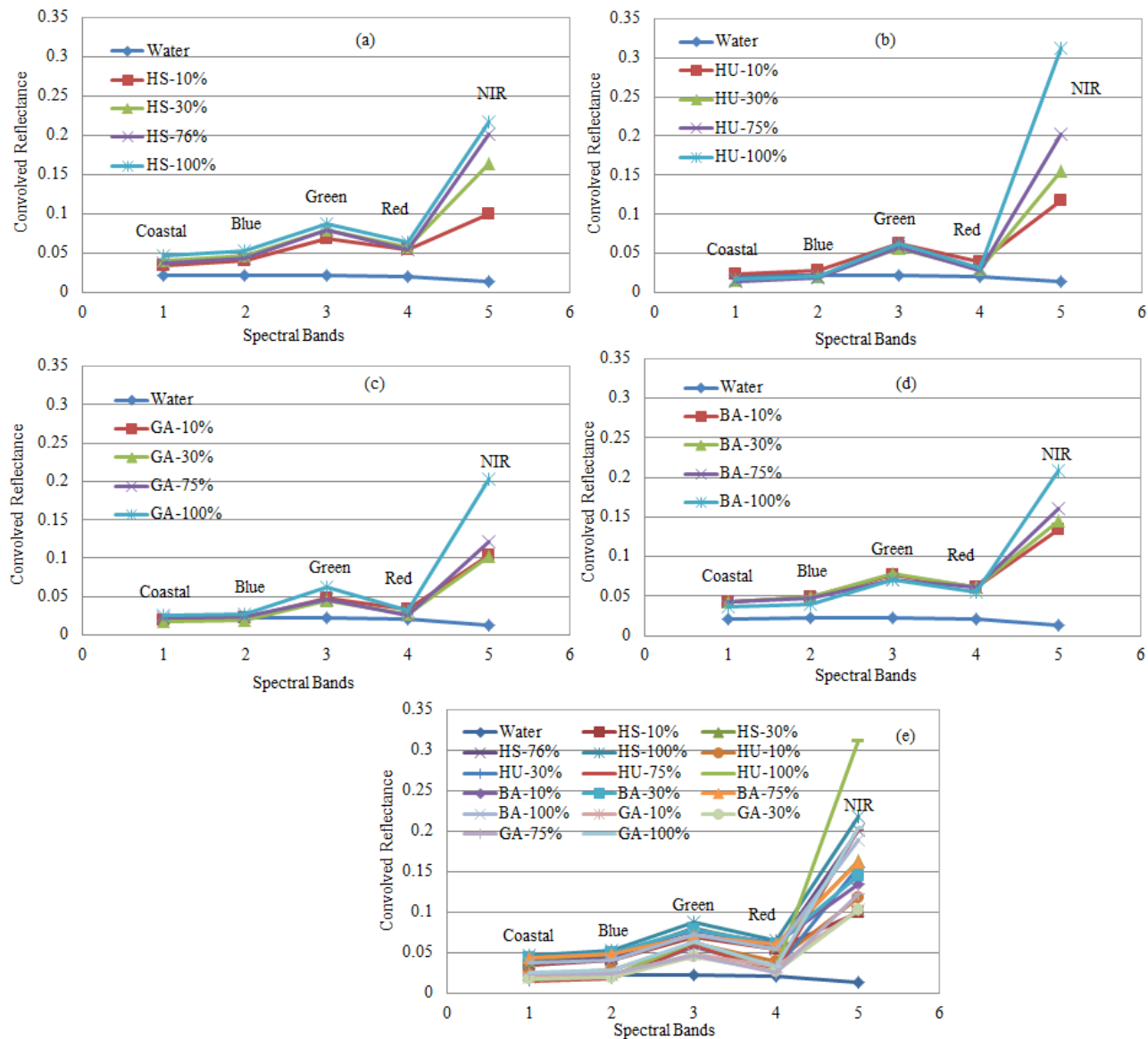

Figure 9. Seagrass, algae, and seawater reflectances resampled and convolved in VNIR bands of Sentinel-MSI (or 

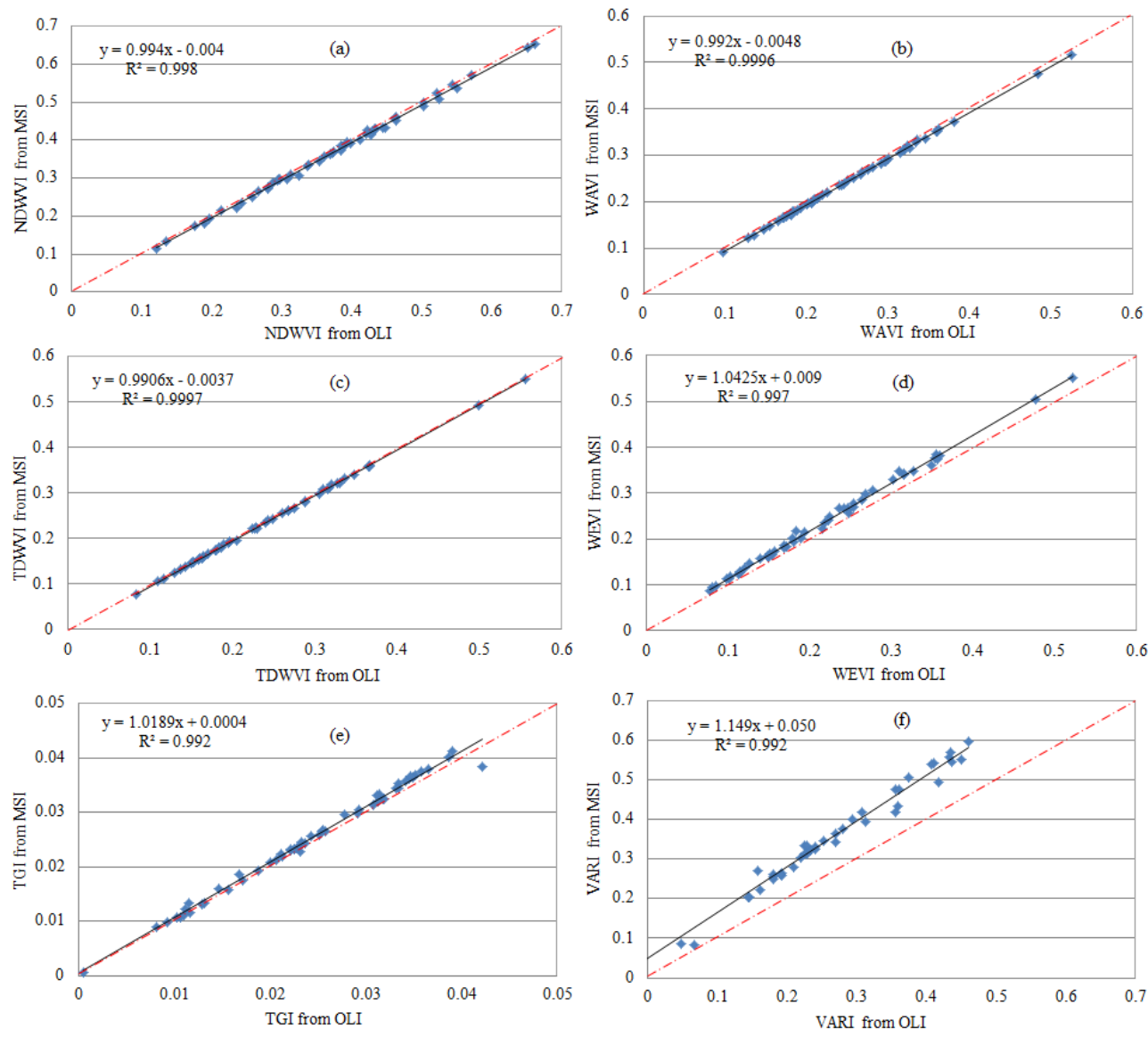

Figure 10. Scatter-plots of homologous WVI derived from MSI and OLI simulated data. 
https://doi.org/10.5194/os-2021-81

Preprint. Discussion started: 25 November 2021

(c) Author(s) 2021. CC BY 4.0 License.

1314
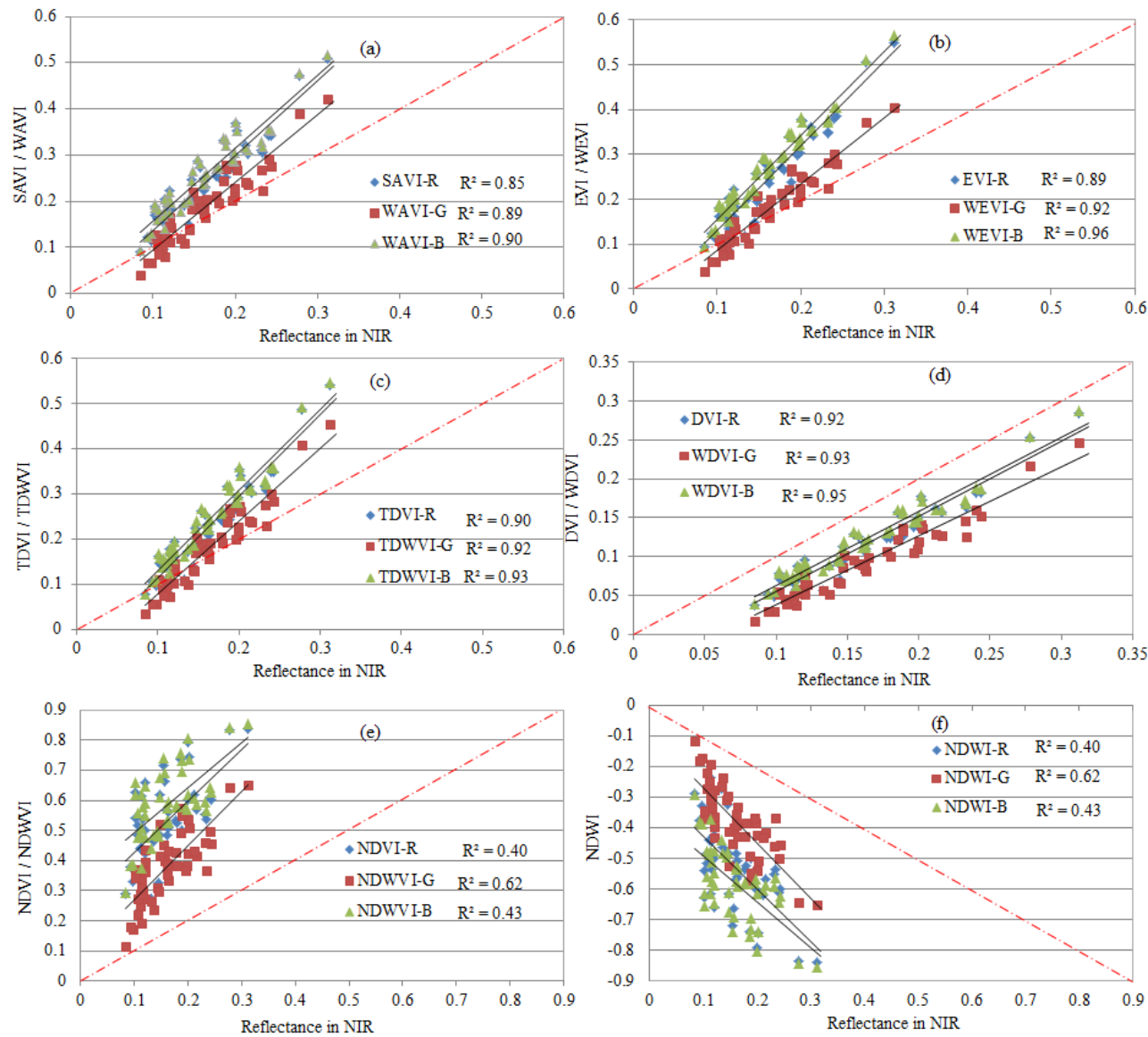

Figure 11. Linear regressions ( $\mathrm{p}<0.05$ ) between WVI and reflectance in NIR considering all samples, and integrating the red, green, and blue bands.

Table 1. The Sentinel-MSI and Landsat-OLI effective bandwidths and characteristics $(\lambda=$ wavelength, SNR $=$ signal to noise ratio, $\mathrm{L}_{\text {ref }}(\lambda)=$ reference radiance, $\mathrm{E}_{0}(\lambda)=$ Extra-atmospheric irradiance, $)$.

\begin{tabular}{|c|c|c|c|c|c|c|c|c|c|c|}
\hline \multirow[b]{2}{*}{$\begin{array}{c}\text { Spectral } \\
\text { Bands }\end{array}$} & \multicolumn{5}{|c|}{ Sentinel-MSI } & \multicolumn{5}{|c|}{ Landsat-OLI } \\
\hline & $\begin{array}{c}\lambda \text { Centre } \\
(\mathrm{nm})\end{array}$ & $\begin{array}{c}\Delta \lambda \\
(\mathrm{nm})\end{array}$ & $\begin{array}{c}\text { Pixel } \\
\text { Size }(\mathrm{m})\end{array}$ & SNR & $\begin{array}{c}\mathrm{L}_{\text {ref }}(\lambda) \\
\left(\mathrm{w} / \mathrm{m}^{2} / \mathrm{Sr} / \mu \mathrm{m}\right)\end{array}$ & $\begin{array}{c}\lambda \text { Centre } \\
(\mathrm{nm})\end{array}$ & $\begin{array}{c}\Delta \lambda \\
(\mathrm{nm})\end{array}$ & $\begin{array}{c}\text { Pixel } \\
\text { Size }(\mathrm{m})\end{array}$ & SNR & $\begin{array}{c}E_{0}(\lambda) \\
\left(w / m^{2} / \mu \mathrm{m}\right)\end{array}$ \\
\hline Coastal & 443 & 20 & 60 & 129 & 129 & 443 & 16 & 30 & 130 & 1895.6 \\
\hline Blue & 490 & 65 & 10 & 154 & 128 & 482 & 60 & 30 & 130 & 2004.6 \\
\hline Green & 560 & 35 & 10 & 168 & 128 & 561 & 57 & 30 & 100 & 1820.7 \\
\hline Red & 655 & 30 & 10 & 142 & 108 & 655 & 38 & 30 & 90 & 1549.4 \\
\hline NIR-2 & 865 & 20 & 20 & 72 & 52.5 & 865 & 28 & 30 & 90 & 951.2 \\
\hline SWIR-1 & 1609 & 85 & 20 & 100 & 4 & 1609 & 85 & 30 & 100 & 247.6 \\
\hline SWIR-2 & 2201 & 187 & 20 & 100 & 1.5 & 2201 & 187 & 30 & 100 & 85.5 \\
\hline
\end{tabular}


https://doi.org/10.5194/os-2021-81

Preprint. Discussion started: 25 November 2021

(c) Author(s) 2021. CC BY 4.0 License.

1323 Table 2. $\mathrm{R}^{2}(\mathrm{p}<0.05)$ between vegetation indices integrating red, blue, and green bands and the reflectances in NIR for all considered samples, and the RMSD between indices derived from MSI and OLI sensors data.

\begin{tabular}{|c|c|c|c|c|c|c|c|c|c|c|c|}
\hline Index & $\begin{array}{l}\text { Used } \\
\text { band }\end{array}$ & $\mathrm{R}^{2}$ & $\begin{array}{c}\text { RMSD * } \\
\text { in \% }\end{array}$ & Index & $\begin{array}{l}\text { Used } \\
\text { band }\end{array}$ & $\mathrm{R}^{2}$ & $\begin{array}{c}\text { RMSD * } \\
\text { in \% }\end{array}$ & Index & $\begin{array}{l}\text { Used } \\
\text { band }\end{array}$ & $\mathrm{R}^{2}$ & $\begin{array}{c}\text { RMSD * } \\
\text { in \% }\end{array}$ \\
\hline \multirow{3}{*}{ NDVI } & $\mathrm{R}$ & 0.40 & 1.0 & \multirow{3}{*}{ TDVI } & $\mathbf{R}$ & 0.90 & 0.3 & \multirow{3}{*}{ DVI } & $\mathbf{R}$ & 0.92 & 0.2 \\
\hline & G & 0.63 & 0.5 & & $\mathbf{G}$ & 0.92 & 0.2 & & G & 0.93 & 0.1 \\
\hline & $\mathrm{B}$ & 0.43 & 1.0 & & B & 0.93 & 0.2 & & B & 0.95 & 0.1 \\
\hline \multirow{3}{*}{ SAVI } & $\mathrm{R}$ & 0.85 & 0.3 & \multirow{3}{*}{ EVI } & $\mathrm{R}$ & 0.89 & 0.9 & \multirow{3}{*}{ NDWI } & $\mathrm{R}$ & 0.40 & 1.0 \\
\hline & G & 0.89 & 0.2 & & G & 0.92 & 0.3 & & G & 0.63 & 0.5 \\
\hline & B & 0.90 & 0.2 & & B & 0.96 & 0.3 & & $\mathrm{~B}$ & 0.43 & 1.0 \\
\hline TGI & & 0.20 & 0.1 & Diff(G-B & & 0.63 & 0.1 & VARI & & 0.63 & 3.0 \\
\hline
\end{tabular}

